\title{
THE ADAPTIVE AND STRATEGIC USE OF MEMORY BY OLDER ADULTS: EVALUATIVE PROCESSING AND VALUE-DIRECTED REMEMBERING
}

\author{
Alan D. Castel
}

\section{Overview}

Why do we remember some events and not others, and how does this change in old age? Although there are a variety of ways to address this question, the present perspective emphasizes how value can have a profound effect on how we use our memory to remember certain information. The ability to select and prioritize what information is important to remember, relative to less salient or peripheral information, is an essential skill for the efficient use of memory. For example, university students seek to memorize information they think is important for a later test, while grandparents may focus on being able to remember information about children and grandchildren, as well as important life events. In both cases, value is used to direct resources toward information that is deemed to be important to remember. The role that value plays in memory performance is critical to develop a comprehensive understanding of how memory is used across the adult life span.

The present summary focuses on how older adults use evaluative processing (a critical process that will be defined and discussed throughout this chapter) to guide encoding and retrieval operations, and how older adults then use value to make decisions about what information is important to remember. In light of the many memory impairments that typically 
accompany aging, older adults can at times be strategic and adaptive, and the evidence for this will be reviewed in terms of how value can guide remembering. Based on this, a conceptual framework is outlined that illustrates how value, goals and prior knowledge, and emotion can lead to qualitative changes in how memory is used by older adults. These changes can lead to memory impairments and errors, as well as the relatively efficient strategic use of memory in old age.

In most laboratory-based memory experiments, participants study long lists of words, word pairs, pictures, or other types of information, with each item or event being equally important to remember for a later memory test. However, it is clear that when we encounter information in the natural environment, not all items or types of information compete equally for attention and memory resources. For example, when we encounter large amounts of information, some units are typically more important than others (e.g., some parts of this chapter are more important to remember than others in order to understand the main points). In order to develop a better understanding of how value influences memory performance, it is critical to take a perspective that acknowledges that memory efficiency is susceptible to the value that is placed on each item, a point that is especially important for older adults. In some cases, older adults may be highly skilled in terms of determining what information is important to remember, relative to younger adults who might have difficulty differentiating what is important to remember and what is of lesser value. Due to lifelong experience with memory operations, older adults may have expertise in terms of being aware of the dynamic parameters and limitations of memory or, in general, knowing that memory is a tool that needs to be carefully regulated and monitored. Of course, the memory impairments and challenges that older adults typically face may be directly related to this expertise, leading to the engagement of adaptive prioritizing that allows for the focus on high value information. It is this ability that is of particular interest in the present summary.

\section{A Selective Review of the Research on Memory and Lifespan Development}

\section{A. Life Span Theories of Cognitive Aging}

Decades of research in cognitive aging has shown a systematic decline in various forms of attention and memory performance, and that this can be attributed to mechanisms that appear to be impaired as a result of healthy, "normal," nonpathological aging (Balota, Dolan, \& Duchek, 2000; Craik \& Salthouse, 2000; Zacks \& Hasher, 2006). Although memory performance can begin to decline as early as the age of 20 years, the most apparent changes are 
observed in later adulthood, typically around the age of 65 years (Park \& Schwarz, 2000; Park et al., 2002). Declines in episodic memory and other types of memory that are thought to be resource-demanding are most apparent for adults older than 65 years, relative to forms of memory which can be classified as semantic, implicit or procedural, and recognition (see Zacks \& Hasher, 2006, for a review). This has led to several prominent theories of information processing and cognitive aging that focus on reductions in available processing and attentional resources (Craik \& Byrd, 1982), general slowing and reductions in speed of processing (Salthouse, 1996), reduced inhibitory control in working memory (Hasher \& Zacks, 1988), impairments in memory for associative information (Naveh-Benjamin, 2000), and the reliance on familiarity due to deficient recollective processing (Jacoby \& Hay, 1998; see also Yonelinas, 2002). Although these theories have received much support, the present chapter focuses more on the qualitative changes that influence the use of memory in old age. Specifically, this chapter outlines the manner in which value can influence how older adults process information, and how value-directed remembering can lead to deficiencies and biases in memory, as well as adaptive performance in terms of the use of memory in old age.

There are several prominent theoretical life span perspectives that are germane to the present discussion of aging and the strategic use of memory. The two most relevant life span perspectives regarding cognitive function in the present context are the selection, optimization and compensation framework (SOC; Baltes \& Baltes, 1990; see also Riediger, Li, \& Lindenberger, 2006, for the adaptive nature of SOC) and socioemotional selectivity theory (SST; Carstensen, 1992; Carstensen, Isaacowitz, \& Charles, 1999). Both of these perspectives are related to the adaptive use of memory resources in old age, resulting in some impairments but, more importantly, a shift in the goals and motivation of older adults.

The conceptual framework of selection, optimization, and compensation posits that successful aging is related to a focused and goal-directed investment of limited resources into areas that yield optimal returns. Thus, older adults can selectively choose certain options in order to maximize performance based on goals, compensating for impairments by optimizing performance in specific goal-related domains. This type of selectivity can be focused on achieving certain goals or can also be "loss-based" (Freund \& Baltes, 2002), as older adults adjust their goals in response to feedback or losses in order to eventually attain desired and realistic goals. In a similar vein, Heckhausen (1999) and Heckhausen and Schulz (1995) suggest that individuals have to take on the regulation of aging-related resource losses in order to function efficiently, which can lead to an improvement in efficient cognitive function. Other compensation-based arguments have been made in the context of neural compensation for the under-recruitment of brain areas 
needed for successful encoding and retrieval (Bäckman et al., 1999; Logan, Sanders, Snyder, Morris, \& Buckner, 2002; Park, 2002), suggesting that perhaps older adults can engage in successful memory processing via the recruitment of additional brain regions. Incorporating neural impairments with behavioral changes is a critical issue, as is considering individual differences in cognitive aging.

SST provides a motivational-based explanation for why age differences are observed in some situations, but not under other conditions, and it specifically addresses the apparent positivity of older adults' reconstructions of past events (Carstensen, 1992; Carstensen et al., 1999). SST suggests that when time is perceived as limited - a perception strongly associated with old agemore emotionally meaningful goals are likely to be pursued, relative to goals that are aimed at gaining new information. For example, older adults are more likely to remember advertisements that emphasize an emotional component relative to knowledge-related information (Fung \& Carstensen, 2003). Thus, SST suggests that older adults have different goals and values (e.g., Blanchard-Fields \& Camp, 1990), such that older adults can regulate emotions in complicated decision-making situations (Blanchard-Fields, 2007), and that this type of processing may be given priority by older adults.

In terms of relating life span development theory to experimental evidence, a useful approach (although not typically incorporated in the area of cognitive aging) has been outlined in Jenkins's tetrahedral model of memory experiments (Jenkins, 1979). This model also emphasizes the sensitivity of memory to context, such that memory performance in a given situation is determined by interactions between four categories of variables: participant characteristics and goals, the cognitive strategy that is necessary for good performance, the nature of the to-be-remembered materials, and the manner in which one assesses performance. Extending Jenkins's ideas to cognitive aging and social cognition, Hess (2005) has suggested that aging is associated with increasing selectivity regarding task engagement in light of perceived or actual declines in cognitive functioning. In general, life span theories focus on a shift in social-cognitive goals from knowledge acquisition in young adulthood to a more emotional and knowledge dissemination focus in old age (e.g., Labouvie-Vief, 1990), and this perspective has implications for how to interpret findings from a variety of memory studies.

Although life span theories typically focus on how older adults direct resources in light of goals and declining cognitive function, younger adults also face certain challenges. In particular, younger adults may have greater access to cognitive resources but may not know how to direct those resources to maximize performance. For example, one challenge students typically face is selecting what information is important to remember for an upcoming examination. Students often ask instructors, "do we need to know this for the 
test," displaying the need to place value on information before committing it to (or making the effort to commit it to) memory (see also Benjamin, this volume). Older adults are often faced with this challenge in a much different domain (outside the classroom, and a somewhat more limited perspective of time, see Carstensen, 2006) - and success in terms of being selective at encoding may be the critical process that leads to the efficient use of memory in old age. By determining what information is of high priority, and ignoring peripheral information, one can limit the information that competes for cognitive resources. This ability, a form of "cognitive control," may be compromised in old age. Such declines may manifest themselves in terms of having difficulty inhibiting irrelevant information in working memory (e.g., Hasher \& Zacks, 1988), as well as being slower and showing more interference in attentional tasks, both at encoding and at the response level (Balota \& Faust, 2001; Castel, Balota, Hutchison, Logan, \& Yap, 2007). However, at more global levels of choosing how to allocate attention, older adults may be able to exhibit control by strategically attending to high value information at the expense of lower value information. This has been demonstrated to some degree by Castel and colleagues $(2002,2007)$, who report that older adults can selectively remember high value information at the expense of lower value information.

\section{B. Motivated Cognition and Goals of Older Adults}

Several studies have examined how motivated cognition and goal-directed memory influence memory performance in old age. Much of this work has examined how emotional information is processed by younger and older adults in the context of veridical and false memories, and the strategic and adaptive use of memory in decision making. The general pattern of findings has been consistent with a positivity effect. Specifically, older adults are more likely to remember positive emotional information relative to negative emotional information, compared to younger adults (Mather \& Carstensen, 2005). For example, Mather and Knight (2005) examined how older adults use cognitive control to direct resources toward positive information while studying and recalling pictures that varied in terms of their emotional valence. Older adults typically recall more positive memories relative to negative memories, and those older adults that scored highly on tests of cognitive control were more likely to show this positivity bias, relative to older adults that scored poorly on tests of cognitive control. For younger adults, cognitive control was not related to the positivity effect. This suggests that older adults need to use cognitive resources to engage in the processes that lead to the positivity effect, implying the need to assign value to the various types of emotional stimuli when prioritizing this information. 
Consistent with this finding, Fung and Carstensen (2003) found that older adults tend to favor and remember advertisements that are consistent with emotional goals, suggesting that emotional regulation can influence and motivate older adults' use of memory.

Since younger and older adults have different goals and motivations regarding memory (and emphasize different forms of value when processing information), this can also lead to certain biases and inaccuracies based on these goals. In the context of decision making and remembering choice features, Mather, Knight, and McCaffrey (2005) examined how analogous or alignable features might be used and (falsely) remembered by younger and older adults. For example, when making decisions about choosing an apartment to rent, or about different health plans, people are often given various features to choose from. Mather et al. (2005) showed that older adults were more susceptible to misremembering or falsely recalling information about features that contrasted with previous options, suggesting that older adults might organize information in a manner that supports accurate memory, but can also lead to false memory. Furthermore, these memory errors were related to performance on tasks that assessed strategic control and frontal lobe function.

In the context of decision making, Wood, Busemeyer, Koling, Cox, and Davis (2005) found that younger and older adults used different strategies when performing the Iowa Gambling Task, which involves the integration of emotion (as assessed by wins and losses) and cognition (use of memory and learning) in a risky-choice decision task. Although younger and older adults eventually reached similar levels of performance on this task, the two age groups used very different strategies that emphasized the strengths and biases of the two groups. Specifically, older adults adaptively used memory for recent emotional events, such as gains and losses (based on valence), resulting in choices that maximized payoff, whereas the younger adults used more specific memory and learning for many prior trials to maximize performance on the task. This suggests that older adults can engage in adaptive decision making in the sense that they will rely on their strengths and assign high value to the emotional component of the task. In contrast, younger adults will perform optimally by using a much different strategy-again suggesting that the two populations function differently with regard to how attention, emotion, and memory are used in decision-making situations.

It is likely that older adults perform better on more naturalistic memory and decision-making tests because they involve more realistic reliance on memory and reasoning (e.g., Rahhal, May, \& Hasher, 2002; Rendell \& Craik, 2002; Tentori, Osherson, Hasher, \& May, 2001). Thus, it may be possible to reduce impairments in the ability to remember information by using materials that lend themselves well to typical memory and decision-making challenges that 
face both younger and older adults outside the laboratory. Such findings are critical because they illustrate how younger and older adults behave differently in situations in which tasks involve more integrated and naturalistic/logical decision making in the context of using memory. The mystery still lies in how these groups weight various components of a task, and the present chapter seeks to emphasize the role of evaluative processing by older adults, leading to adaptive and efficient performance (cf. Schacter, 1999). The manner in which value is subjectively and internally assigned to information, such as choice features, positive and negative emotional valence, or components of a decision-making process, is a critical process. Older adults may in fact be more aware of the need to use value to guide encoding and retrieval, relative to younger adults, and it is this observation that might reinforce the need to prioritize how information will be processed in order to lead to efficient memory performance.

\section{Strategic Control and Value as Memory Modifiers for Older Adults}

\section{A. Value as a Memory Modifier for Older Adults}

The debate regarding what makes people value certain things has been a central issue in many disciplines, particularly in psychology and economics. Adam Smith's classic example of something with high value was water (Smith, 1776/1994). As suggested by Smith, the practical theory of value (also known as the intrinsic theory of value) stated that an object's value was rooted in how useful it is to the individual. Although this concept of value seems straightforward, one perplexing question which has been asked is that if indeed this theory were true, why do diamonds (which had, at the time, little practical use) command a much higher price than water (which is utterly crucial to existence and survival)? This problem was known as "the diamond-water paradox," as it seemed to make very little sense in most contexts - and in the case of memory, a similar dilemma might exist. Remembering essential and functional information may be placed at a premium, possibly at the expense of other important and valuable information, and being able to make this distinction (i.e., selection and focusing) is critical for the efficient use of memory. In the context of what information is of high value when encoding new information and remembering past events, this depends on the point of view of the rememberer and the functional significance of the information (e.g., Nairne, 2005), with differences likely to be evident between younger and older adults.

In a similar view, both Hess (2005) and Jenkins (1979) emphasize that memory research needs to take into account the goals of the rememberer and 
context in which information is studied in order to provide a clear account of how people attempt to remember information. Thus, value or relevance to the individual is a perspective that should be considered in light of how memory is used in old age. This perspective has also been taken in decision making and in the context of behavioral economics. The behavioral economics behind focusing on high value information is a concept that is critical to the arguments made here regarding memory and aging and is thought to be governed by strategic evaluative processing at encoding. In general, economists use the term "strategic" such that something will yield high returns from limited resources; it may be that older adults also function this way when it comes to memory. Thus, examining memory and aging in context requires knowing how value, and the assignment of value (via evaluative processing), place a premium on the goals and motivation of the rememberer (e.g., Hess, Rosenberg, \& Waters, 2001), possibly leading to efficient memory use in old age.

Since the concept of value has been studied in a variety of contexts (e.g., economics, bioethics, and psychology), before expanding on the role of value in memory, it is important to provide a clear and functional description of the terms used in the present argument. Specifically, this chapter uses some critical but common terminology that requires some careful description given that these terms are often used in a variety of contexts. These terms include strategic control, value, evaluative processing, selectivity, and grain size. In the present context and arguments, strategic control refers to the ability to focus and direct resources on high value information, giving high priority to information that is deemed to be important, in either a subjective or an objective sense. It is strategic in the sense that ideally this allows for selective optimization (somewhat similar to SOC), much like an investor might allocate funds strategically in order to maximize returns without taking costly risks. Strategic control can also (ideally) be adaptive, such that strategic allocation of resources can be altered, adjusted or biased based on upcoming or anticipated goals and in light of current capabilities. Although this can be partially related to and mediated by a more general construct of "cognitive control," it is different than how the term "strategy" has often been used to describe specific encoding strategies such as imagery, peg-word systems, elaborative processing, and other self-initiated strategies that appear to be reduced or impaired in old age (cf., Hertzog \& Dunlosky, 2005). Value in this context does not refer to ethical or moral value, but rather the importance or weight that is assigned to information, such as in economics in which value is often determined by availability and demand of a commodity in relation to its price per unit. Value can be both objectively and subjectively defined, and can depend on the situation (the need to remember certain high value information) and experience (prior knowledge and expertise can dictate what is high value) of the individual. 
Assigning value or utility to characteristics or options in the context of decision making has been a central component to theories regarding choice behavior (Tversky, 1969, 1972), but in the context of memory research very little emphasis has been placed on value of the to-be-remembered item, and how older adults might use value to guide encoding and retrieval operations. Evaluative processing is the mechanism in which value is assigned to information by the rememberer, and this can be influenced by a variety of factors. Most typically it is based on how important the information is for the current goal of the individual, whether this information is consistent or inconsistent with prior knowledge, as well as motivation and anticipated future use of this information (e.g., Hess et al., 2001). The term selectivity refers to focusing on certain items or events that are perceived to be of high value, possibly at the expense of lower value information. As suggested by Riediger and Freund (2006), a more general form of "motivational" selectivity may involve two forms: (1) Focusing on high value/important information, while also (2) restricting the access of lower value or more peripheral information. Although the present chapter centers on the "focusing" mechanism involved in selectivity, older adults may have greater difficulty with the restricting component (as suggested by Hasher \& Zacks, 1988, in terms of working memory), leading to the encoding (but not necessarily the later use) of peripheral perceptual information (e.g., Koutstaal, 2003). Finally, older adults may be able to maximize memory performance using appropriate "grain size" at encoding and retrieval (Goldsmith \& Koriat, this volume; Goldsmith, Koriat, \& Weinberg-Eliezer, 2002; Koriat \& Goldsmith, 1996). Grain size is defined as the level of detail ("precision") or generality ("coarseness") at which to encode and later report remembered information (Goldsmith et al., 2002), and older adults might more often rely on more general/coarse, gist-based retrieval in a variety of settings.

Older adults clearly have different goals relative to college students, in terms of memory performance in the context of life span development, and possibly also on laboratory-based memory tests, so it seems somewhat problematic to compare older adults to younger adults in these types of situations. Older adults have not typically been accustomed to memorizing large amounts of information, using esoteric methods to commit arbitrary information to memory, and the constant tests that college students typically encounter. Younger adults who are college students could in fact be classified as "expert memorizers," in a much different sense than older adults are experts in certain domains, given the emphasis that is often placed on memorizing information and terminology when studying for examinations, perhaps at the cost of being selective. Older adults use evaluative processing to selectively remember only certain types of information, often at the cost of being able to remember large amounts of information, or specific arbitrary details. 
Given the somewhat different abilities and perspectives on the use of memory by younger and older adults, it does not seem surprising that age differences exist in a variety of laboratory-based memory tests. The real surprise comes from situations in which older adults' memory performance is similar to younger adults, given their somewhat different approach to memory tasks. Thus, it seems that older adults who participate in memory experiments differ in both a quantitative sense (less capacity to remember long lists of items) and qualitative sense (different approach regarding what information is important to remember), and both of these factors lead to differences relative to younger adults. For this reason, it seems necessary to take caution when comparing younger and older adults on tests of memory, given that differences in performance could potentially result from qualitative and/or quantitative reasons - a point that plagues any type of crosssectional design in cognitive aging research that directly compares younger college students to older adults. Although there is no immediate solution to this issue, by experimentally manipulating the value of to-be-remembered information, or considering how different age groups use evaluative processing in this context, cognitive aging research can assess important differences and similarities in how younger and older adults can efficiently use memory.

\section{B. Selectivity, Value, and the Use of Memory by Older Adults}

One useful way to examine the impact of value on memory performance in an experimental setting is to have to-be-remembered items in a list assigned a range of different values. This is in contrast with most of the typical memory experiments in which each item, picture, or word pair is of equal importance to remember for a later memory test. By assigning different values to to-beremembered items, one can determine how participants use value to guide encoding and retrieval processes. Furthermore, as participants become more aware of how easy or difficult it is to remember information, one can observe how strategic control is exerted such that participants begin to focus on high value information. In the "selectivity" paradigm (Castel, Benjamin, Craik, \& Watkins, 2002; Castel, Farb, \& Craik, 2007; Watkins \& Bloom, 1999), participants are presented with a list of 12 words, and each word is paired with a different numeric value ranging from 1 to 12 (e.g., table 5, uncle 9, apple 2, pilot 6..., see left panel in Fig. 1). In some variants of this procedure, the value is presented immediately after the word to ensure that participants do not simply ignore low value words. Participants are told that they should try to remember as many words as they can for a later recall test, such that they maximize their score. The score is the sum of the value of the recalled words, and the experimenter informs participants about their score once they have recalled the words. Based on this feedback, participants are encouraged 
A

Ancle 9
Apple 2
Pilot 6
Berry 11
Cabin 1
Skate 7
Cheek 12
Fence 3
Straw 8

Petal 10

Drain 4
B

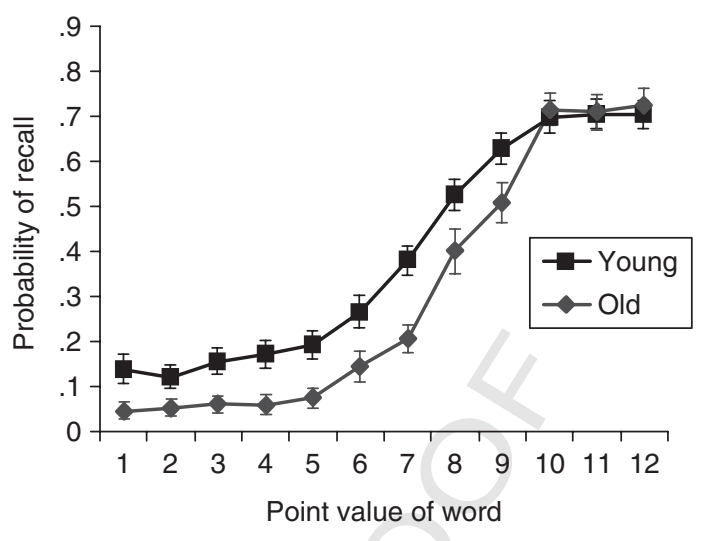

Fig. 1. The procedure (A) and results (B) from the selectivity paradigm, which allows for an examination of how participants use value to guide encoding and retrieval processes. (A) The participants are presented with a list of 12 words (one at a time), of which each word having a unique value ranging from 1 to 12 , and the values are randomized across the serial positions. Participants recall the words with the goal to maximize their score. Participants then repeat this with a new list, are given feedback about their score, and are given many successive trials with new lists and feedback about their score. (B) The results in terms of the probability of recall for younger and older adults as a function of point value (adapted from Castel et al., 2002; Castel, Farb et al., 2007). There are no age differences for high value information (12-, 11-, and 10-point words), whereas age differences exist in memory performance for other lower values.

to remember the high value words in order to maximize their performance, though recalling any word will lead to a higher score.

The results from selectivity experiment are displayed in the right panel of Fig. 1 in which the probability of recall is plotted as a function of point value. Younger adults perform quite well and on average recall more words than older adults, but in some instances do not appear as selective, as they recall both high and low value words (Castel, Benjamin et al., 2002). What is interesting about this is that after some experience with the task (participants are given numerous unique lists, one after another), participants become aware that they cannot remember all of the words (as the words are presented fairly rapidly at encoding). Thus, some participants begin to focus or select the highest value words to remember in order to efficiently boost their score. Older adults were in fact quite efficient in terms of selectively remembering the high value words (i.e., the 12-, 11-, and 10-point value words), in light of knowing that they will likely only be able to remember three or four words. Although a general impairment in memory in old age would predict that younger adults would recall more information at each point value, and an 
inhibitory impairment would predict that older adults would recall more low value words, the results suggest that older adults can direct attentional resources to high value information. Thus, for the high value information (12-, 11-, and 10-point words), there are no age differences in memory performance, while age differences do exist for lower value information.

It is important to note that participants were told their score after the recall of each list (and were then given another new list - in some cases doing this up to 48 times!), so it is likely that after the first few lists participants began to be more selective in order to maximize their score. An efficiency index was also calculated, which compared the participant's score relative to an ideal score based on the number of words recalled. For example, if you recalled three words (the 8-, $10-$, and 12-point words), an ideal score would be $10+11+12=33$ (i.e., recalling the top three words), and if your actual score was $8+10+12=30$, then your efficiency index would be your actual score divided by the ideal score, actual/ideal $=30 / 33=0.91$ (see Castel, Benjamin et al., 2002, for more details about the selectivity index). When the selectivity index was calculated for both younger and older adults, under certain conditions (such as immediate free recall), older adults displayed a higher selectivity index as they would consistently just recall the top three or four words, whereas younger adults would recall high and some additional low value words. Although this index may be somewhat biased, given that younger adults recall more words in general of varying value, it does provide a useful measure in which older adults displayed greater efficiency in terms of selectivity.

To illustrate how older adults learned to become more efficient in the selectivity task, performance (in terms of the selectivity index and proportion of words recalled) was plotted as a function of list, and displayed in Fig. 2. Recall performance improved slightly after the first few lists and then remained stable. Although older adults did not display high selectivity for the first few lists, after several lists older adults became more selective in terms of focusing on encoding higher value items, leading to higher efficiency scores as reflected by the selectivity index. Although not shown in the figure, younger adults showed a similar trend with higher overall recall. Thus, it may be necessary for older adults to learn about how to be efficient, and this requires some experience with the task (and may be related to other changes in strategy and control by older adults, e.g., Spieler, Mayr, \& LaGrone, 2006; Touron, 2006). It may be that older adults might engage in an efficient form of event-based prospective memory with practice (e.g., McDaniel, Einstein, Stout, \& Morgan, 2003), in terms of remembering to remember higher value information, as this is reinforced with many trials and feedback about score in the selectivity paradigm.

The findings from the selectivity paradigm suggest that older adults can direct attention to high value information. However, it was not clear how 


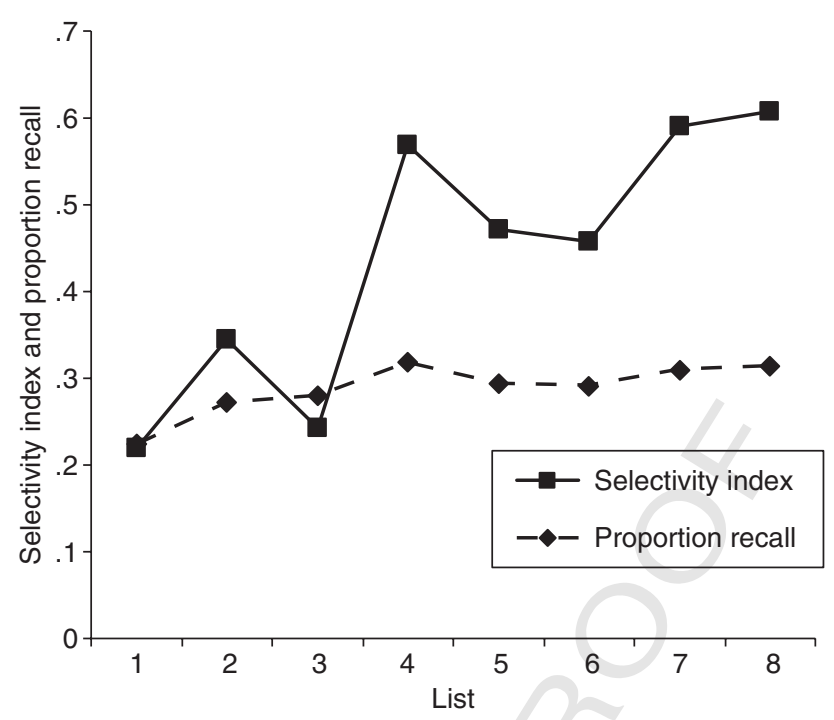

Fig. 2. The selectivity index (derived from participants' score relative to an ideal score) and proportion of words recalled as a function of list order for older adults (adapted from data in Castel et al., 2002; Castel, Farb et al., 2007).

value was represented in memory by older adults. In order to examine how older adults represent value that then leads to selectively guiding encoding and retrieval processes based on value, Castel, Farb et al. (2007) specifically tested how older adults recalled the value of the presented item. It may be the case that older adults simply determine which words are of high value (but do not remember the precise value), and this heuristic then guides encoding of high value information. Older adults might quickly encode a high value word (e.g., cheek 12) as important, and not remember the precise value after encoding, but rather the general level of importance (i.e., a coarse grain size). Thus, Castel et al. tested how well younger and older adults could recall specific value information, to see if younger adults could remember more specific value information, while older adults focus on remembering range information regarding value, given comparable abilities to remember high value words. The results were that both age groups were equally good at recalling point values when recalling the range of high value words, but younger adults outperformed older adults when recalling specific values. These findings suggest that although both groups retain value information, older adults rely more on gist-based encoding and retrieval operations with regard to high value, while younger adults are able to remember specific 
value information. This may represent a heuristic at encoding, such that older adults convert information from precise numerical information to a more general value level that is then bound to the item, and this facilitates memory for high value information.

In order to examine the degree of control that younger and older adults can use when value guides remembering, Castel, Farb et al. (2007) employed a selectivity procedure in which words were paired with either negative or positive point values. Thus, participants should focus on high value positive information, but restrict encoding and retrieval of lower value information, and especially information of negative value. The incentive to focus on positive value in this case was reinforced, as participants were instructed that recall of negative value information would actually lead to a reduction in their score. Results showed that both younger and older adults recalled only the positive value information, again with no age differences for the highest value information. Interestingly, much like younger adults, older adults did not recall any of the negative value information. However, on a later surprise recognition test for all items, older adults were in fact more likely to recognize the negative value words. These data suggest that older adults did, in fact, process these words perhaps due to poorer inhibitory control, and likely took longer to code them as negative value information (perhaps due to slowing; Salthouse, 1996).

The observation that older adults do in fact encode negative, low value or irrelevant information is consistent with impairments in inhibitory control in the directed forgetting paradigm. In this task, participants are given instructions to remember or forget certain items after initial encoding, with older adults recalling more of the "forget" items under certain conditions, suggesting that older adults cannot inhibit the encoding and later recall of these items (e.g., Zacks, Radvansky, \& Hasher, 1996). However, the directed forgetting paradigm does not allow for the examination of how value can influence control over encoding - a critical issue in the present context, given that older adults often rely on value to guide encoding operations. Thus, the idea that older adults can prioritize what information to commit to memory may have important implications for training efficient use of memory. Rather than focusing on encouraging older adults to use techniques that typically help younger adults, such as improving recollection or enhancing the capacity of working memory, it may be helpful to enhance and emphasize the various mechanisms associated with selectivity, such as focusing on high value information, and restricting the access of lower value information-especially in situations in which both types of information compete for attention.

The notion that value can influence memory performance has also been examined in applied areas of psychology, such as eyewitness identification. In a study by Leippe, Wells, and Ostrom (1978), students witnessed a staged 
theft in which a purse that contained either an expensive object (i.e., high value, such as a diamond ring) or an inexpensive object (i.e., low value, such as a pair of gloves) was stolen, and subjects were either told of the value before or after the theft. When witnesses had prior knowledge of the object's value, accurate identification of the thief was more likely when the theft involved a high value item, relative to the low value item. However, when knowledge of the crime's seriousness was gained after the theft, then knowledge of the value of the item had little effect on the ability to later identify the thief. Thus, the perceived seriousness of a crime or knowledge of the value of the stolen item can influence encoding operations, possibly via the recruitment of attentional resources in relation to the degree of value of the items or seriousness of the crime.

This approach of "value-directed remembering" by both younger and older adults, as shown in the selectivity paradigm and other instances, can thus serve several purposes in terms of the theoretical and applied aspects of strategic control of memory in old age. First, following the work of others (e.g., Hess, 2005; Mather \& Carstensen, 2005; Baltes's SOC theory; Zacks \& Hasher, 2006), it informs clinicians and researchers regarding situations in which memory performance can be optimized for certain materials and certain contexts. Second, it outlines how future research can determine boundary conditions in which value influences memory performance in older adults. Finally, and perhaps most importantly for memory improvement in old age, it suggests ways in which older adults can become (or already are) expert users or students of their own memory in order to be most efficient when using memory. This can be accomplished by knowing the limitations of memory, and selectively allocating resources to important information.

\section{Evaluative Processing as Skilled Cognition in Old Age?}

Evaluative processing can have benefits, but in many laboratory-based memory tasks it can lead to negative consequences (see Hess, 2005, p. 389). Namely, older adults will often report more thoughts or feelings about to-be-remembered items which can then lead to poor source memory. For example, when encoding and processing unrelated word pairs for a later memory test, older adults often note (aloud) how the words are unrelated and "don't go together," whereas younger adults engage in elaborative processing to link the unrelated words, such as creating a far-fetched story or using elaborate forms of imagery. Thus, older adults have difficulty remembering these associations because at encoding they fail to make a link between the two words (see Naveh-Benjamin, 2000). If anything, older adults often report that the words are unrelated, and then appear to cease processing the pairs as this incongruent relationship between the arbitrary words is of low value to them to later remember (despite the instructions of the experimenter to remember all of the word pairs for a later 
test). Although other work attempts to measure the elaborative processing, or tries to equate elaborative processing for younger and older adults (see Hertzog \& Dunlosky, 2003; Naveh-Benjamin, Keshet, \& Levi, in press), it seems that there is a qualitative difference in the approach that is used by younger and older adults that is not captured via these measures.

In a similar vein, when information is related to, or somewhat inconsistent with, older adults' prior knowledge, evaluative processing can be especially helpful. Castel (2005) examined how younger and older adults can link grocery price information with grocery items, with the grocery prices either reflecting market value (e.g., milk \$3.79), or unrealistically high or low prices (e.g., butter, \$17.89). Participants studied various item-price pairs, and were later presented with the grocery items and had to recall the prices paired with each item. Younger adults were much better than older adults at recalling the unrealistic prices, but there was no age difference for the realistic prices (see Fig. 3). While studying items, older adults would verbally report that the over- and underpriced items were unrealistic. For the market-value items, older adults engaged in more specific evaluative processing, likely supplemented by prior knowledge at encoding in which they compared prices with what they usually paid for these items. In fact, older adults would often

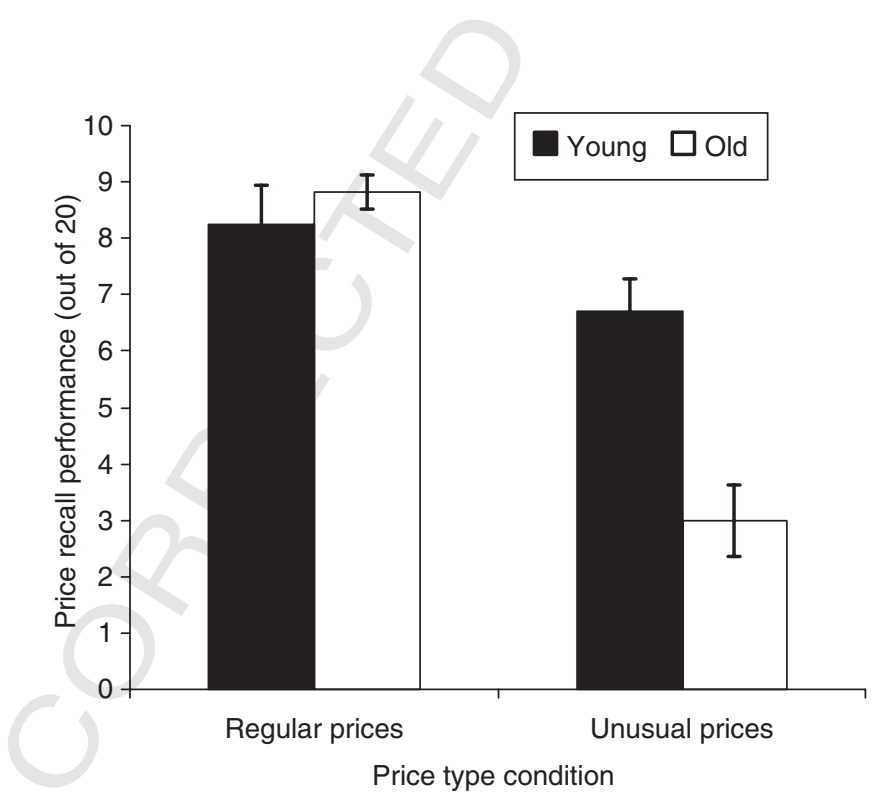

Fig. 3. The number of correctly recalled (exact) prices by younger and older adults for market-value-priced and overpriced grocery items (from Castel, 2005). 
report that market-value prices were either slightly more or less than what they might pay, whereas younger adults were good at simply memorizing the prices for all of the items. Again, this suggests a qualitative difference in the approach that was used by the two groups, with older adults using evaluative processing and reliance on prior knowledge to encode information in order to supplement memory performance.

\section{Value, Motivation, and Emotional Priority FOr Older Adults}

Although older adults are often motivated in terms of trying to remember various types of information, it is important to describe the boundary conditions regarding what/how motivational factors can influence memory performance in old age. Often older adults who participate in memory experiments are analytical of the materials that they need to remember (e.g., unrelated word pairs), and state this at some point during the experiment, possibly reflecting the difficulty that they have encoding and retrieving the information. However, this might represent an important difference between younger and older adults; whereas younger participants simply memorize the information in question, older adults will be critical of why they need to remember somewhat arbitrary information-perhaps reflecting the use of selectivity. Just as in the infant and child development research that employs materials and stimuli that the participants find of value and can commit to memory, it is critical that the materials that are used to test older adults' memory also share these essential features. Although memory research in general has been criticized for lack of naturalistic materials or generalizability to the real world (Neisser, 1982), it is not simply enough to use materials that older adults have experience with-value needs to be incorporated into tasks, either in terms of the subjective or objective measure of how value influence how older adults use their memory.

One example of how motivation might contribute to memory performance is in terms of the emotional context in which information is encoded. Although there is some debate as to how emotion enhances binding that occurs in working memory (Mikels, Larkin, Reuter-Lorenz, \& Carstensen, 2005), and whether emotion helps or hurts memory for central and peripheral information for older adults (Kensinger, Piguet, Krendl, \& Corkin, 2005; see Mather, 2007, for a review), the emotional context of incoming information plays a critical role in how older adults process and prioritize this information. In general, compared to younger adults, older adults report being more efficient at regulating their emotions and focus more on emotion regulation (Diehl, Coyle, \& Labouvie-Vief, 1996). This increased focus on regulating emotions seems to influence their everyday information processing, as they show a positivity bias 
in their attention toward information, favoring positive over negative information (e.g., Mather \& Carstensen, 2003; Mather \& Knight, 2005; Mather et al., 2005; for a review see Mather \& Carstensen, 2005). Older adults also exhibit this bias for emotional items in working memory (Mikels et al., 2005). These agerelated attentional biases may amplify the effects of arousal on memory binding for certain positive stimuli and diminish them for negative stimuli (e.g., Mather, 2006). However, another way to interpret this bias is that positive information is assigned higher value in old age, leading to older adults focusing and prioritizing based on this assigned value. The assessment of what receives high value can differ as a function of the person's experience and expertise (are older adults in fact experts in terms of emotional regulation?) as well as during certain situations in which specific types of information are important or salient.

\section{Model, Review and New View of Value, Memory, and Aging}

\section{A. A Model of Evaluative Processing and \\ VAlue-Directed Remembering}

Given the need to understand how value can influence memory performance in old age, a conceptual framework (which is illustrated in terms of a model of information flow from encoding to retrieval) is presented in Fig. 4. This framework is intended to model the influence of value-directed remembering across the life span (i.e., for both younger and older adults), and highlights

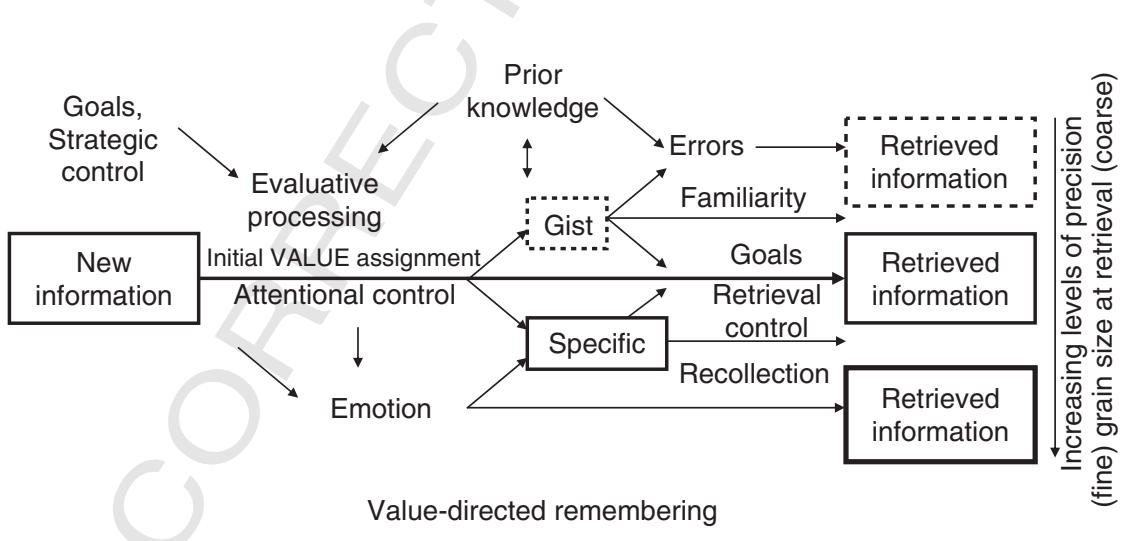

Fig. 4. A conceptual framework that models the flow of information in memory based on value-directed remembering, with an emphasis on evaluative processing at encoding, and different levels of grain size at retrieval. 
and summarizes the arguments made in this chapter. This framework emphasizes the role of evaluative processing at encoding, leading to selectivity as a filter once value has been assigned to new information. The utility of this framework is that it seeks to account for why in old age value-directed remembering becomes increasingly important and attempts to explain how value-directed remembering can account for some of the important findings in the domain of memory and aging. This model incorporates processes involved with value assessment relative to goals and prior knowledge at encoding, with attentional control needed to then bind this information (content plus its assigned value) for later processing. Thus, the theory that governs value-directed remembering can be described as "strategic and selective control theory," in that older adults can compensate for memory impairments by being strategic in what they choose or select as information to remember, which varies based on the ability to control or direct attention to important information.

The role of value assignment is a critical and under-defined process that occurs at encoding, and is thought to involve both objective and subjective factors, depending on the situation (the need to remember certain high value information) and experience (prior knowledge and expertise can dictate what is high value). Value is assigned via evaluative processing of the incoming information, and value can be represented in various forms. Evaluative processing relies on both attentional and emotional control, leading to the assignment of value based on a number of factors that are specific to the individual and context (e.g., Hess, 2005; Jenkins, 1979). It should be noted that value-directed remembering can be governed by both objective value (e.g., high value words in the selectivity paradigm, as dictated by the experimenter), and subjective value (e.g., the rememberer assigns a value that can differ based on the individual and context, such as grocery prices or emotional words). Further research is required to examine how these two forms of value can direct memory and be modified to maximize memory performance, and how memory training for older adults can focus on objective value in order to enhance memory for detailed information.

Depending on the value assigned to incoming information, the information is then represented in either a specific verbatim form, or in most cases a more general but semantically rich gist form. Information that is represented in a specific form can then support recollection at retrieval, resulting in a more precise grain size and highly accurate remembering. However, older adults typically draw on information from gist-based representations, which can be then supplemented with prior knowledge and inferences (see Reder, Wible, \& Martin, 1986) — sometimes leading to specific and predictable memory errors that are consistent with prior knowledge. Gist-based processing typically leads to familiarity at retrieval, translating to somewhat less 
precise but still useful retrieval of information. The degree or precision or grain size of retrieved information is then illustrated in terms of how accurate one can be when recalling details (e.g., remembering there were 43,567 steps on a hike to Machu Picchu, vs. recalling it was about 40,000 steps; or that your flight leaves at 12:06 PM, or just around noon), but can also lead to certain types of memory errors.

The model and theory of strategic and selective control of value that guides this explanation of value-directed remembering centers on how older adults can use evaluative processing to direct memory resources toward important information. According to this theory, impairments in a variety of tasks and situations may be ameliorated if older adults can strategically adapt to encoding large amounts of information by judging how important the information is for future use. Older adults can thus compensate for impairments in capacity by limiting the amount of information that one attempts to remember (see Benjamin, this volume, for the use of electronic alternatives for storing and access information). This also suggests that older adults might use (or need to use) broader grain size or familiarity as an adaptive form of retrieval in light of impairments, but also the judicious use of value in terms of deciding what information requires precise encoding and recollective processing at retrieval.

The processing of emotional information has also been highlighted in the model and is based on the notion that evaluative processing of emotional information leads to an assignment of high value, or priority binding (e.g., MacKay, Hadley, \& Schwartz, 2005), for this type of salient information. SST suggests that the processing of emotional material is often consistent with older adults' goals, and for this reason it is assigned high value in the model (see also Mikels et al., for a similar account that involves working memory resources). As stated by Mather and Carstensen (2005), attentional control can lead to biases in the way negative and positive emotional material is processed, with positive emotional material being better remembered by older adults. In the model, positive information is bound to a high value variable as a result of attentional control, or in other cases high value assessment, leading to direct access of this information via recollection. Negative emotional material, although still assigned a high value during evaluative processing, is then differentiated from positive emotional information and stored in a specific manner, but not given the same priority and recollective nature as positive emotional information (and in some cases negative information could be ignored if it is of sufficiently low value). This is especially the case when both negative and positive emotional information are encountered at a similar time, leading to relative comparisons and a highly observable positivity effect at retrieval, based on recollection. This then explains the 
finding of a greater bias or positivity effect for mixed lists relative to lists that contain only positive or negative information (e.g., Grühn, Smith, \& Baltes, 2005). However, although emotional materials lend themselves well to the model in terms of evaluative processing and priority, in the following section other domains of impaired memory performance will be covered, in order to illustrate how the evaluative processing (as described in the model) can account for some important findings in the literature, especially in terms of the strategic control that is used by older adults.

\section{B. General Slowing, Metacognition, and Evaluative Processing}

One dominant explanation of cognitive aging suggests that older adults experience a general slowing of cognitive processes (Salthouse, 1996), and can be applied to changes in neuronal function as well as slower reaction time for older adults. Such slowing can explain a number of the impairments observed in working memory function, leading to deficits in long-term episodic memory. Typically, age differences in memory tasks are most pronounced when tasks require speeded response (e.g., Stine, Wingfield, \& Poon, 1986). However, in many situations older adults can compensate for slowing by taking longer to encode and retrieve information. Thus, some strategic control over retrieval processing might contribute to older adults taking more time at retrieval (although often studies attempt to account for this by giving older adults more time than younger adults). It may even be the case that older adults should be encouraged to take more time in order to engage efficient encoding and retrieval operations, as opposed to simply relying on familiarity and gistand perhaps value can dictate how older adults should allocate study time and resources.

Strategic and selective control theory would posit that older adults can maximize memory performance in situations in which they are free to use controlled processing, and slower and self-initiated engagement of memory. For example, Benjamin and Craik (2001) found that younger adults' source memory under speeded response conditions resembled that of older adults. Jacoby (1999) has found that repetition at encoding can lead to greater use of familiarity by older adults in the process dissociation procedure. Together, these studies suggest that speeded conditions and repeated presentations can lead to the unopposed use of familiarity. When value is assigned or attached to items, it may be that older adults can thus compensate and benefit from studying fewer items but remember these items well, and can self-select how to allocate study time to high value information. Along these lines, Dunlosky and Connor (1997) found that both younger and older adults allocated extra 
study time to items that they judged as difficult to remember. In addition, judgments on one trial and study times on the next trial were negatively correlated, suggesting that both younger and older adults utilized monitoring to efficiently allocate study time to material that required extra time (although the magnitude of these correlations was less for older than for younger adults).

The global use of metacognitive skills are crucial for older adults, and in some cases aging does not impair the monitoring of encoding, even though aging adversely affects associative learning (Hertzog, Kidder, Powell-Moman, \& Dunlosky, 2002). Importantly, older adults can learn to effectively monitor associative learning via training with retrieval and self-testing (Dunlosky, Kubat-Silman, \& Hertzog, 2003), as also shown in the selectivity paradigm (Figs. 1 and 2). What is of interest is to extend this metacognitive work with items of different values to determine whether older adults can sufficiently allocate study time to high value information and spend minimal time encoding low value information. Thus, in light of slowing and reduced capacity, older adults' memory performance may be made more efficient with a shift in self-paced study time from low to high value information (and encode this information with greater confidence and accuracy), while younger adults may not (need to) be as selective under these circumstances.

\section{Associative Memory Impairments and Value}

The ability to link units of information to form more complex representations of the past is a critical function of memory. One explanation for older adults' poorer episodic memory performance is based on impaired binding (Chalfonte \& Johnson, 1996), leading to an associative deficit (Naveh-Benjamin, 2000). This is supported by many observations that older adults have greater difficulty remembering source information (Johnson, Hashtroudi, \& Lindsay, 1993), the context in which information was previously presented (Spencer \& Raz, 1995), the link between two units of information, such as names and faces (NavehBenjamin, Guez, Kilb, \& Reedy, 2004), and, in the laboratory, unrelated words pairs (Castel \& Craik, 2003; Naveh-Benjamin, 2000). However, age differences are negligible in terms of memory for related word pairs. Thus, an associative deficit hypothesis (Naveh-Benjamin, 2000) can partially explain many of the memory errors that older adults experience when trying to remember arbitrarily related associative information.

However, this associative impairment does not fully explain findings in which older adults can in fact use and remember source information in certain circumstances. Typically, older adults display impairments in remembering source information (Schacter, Kaszniak, Kihlstrom, \& Valdiserri, 1991). However, in a source memory experiment by Rahhal et al. (2002) it 
was shown that although older adults had difficulty remembering the voice (male or female) in which a statement was heard, when older adults were told prior to study that the speaker's voice indicated whether the statement was true or false they displayed good memory for the "truthfulness" of these statements. Thus, it may be that when an associative memory task involves binding arbitrary bits or units of information (e.g., a voice with a statement, unrelated word pairs, or numbers with words), older adults display associative memory impairments (e.g., Castel, 2007). However, when the memory task involves more meaningful and naturalistic associative information, which involves older adults placing a greater value on the source of information, age differences are reduced or eliminated.

Naturalistic and emotional content can also influence how source memory information is processed and retained by younger and older adults. May, Rahhal, Berry, and Leighton (2005) showed that when emotional information was conveyed by the source, older adults could remember source information about where food was located (left or right side of a room), if this information was coupled with high value meaning (food of the left was poisonous while food on the right was fresh). Although May et al. interpreted this in terms of emotional content, value plays a critical role in how older adults process source information, and when source information conveys critical information, older adults seem able to remember this form of source. Finally, value formation can also be dictated by experience, particularly when older adults engage in evaluative processing, such as when remembering the prices of grocery items. As stated previously, Castel (2005) has shown that older adults can remember price information (an item and its exact price) only when the price reflects market value, but not when the prices are greatly exaggerated, suggesting that older adults require and benefit "schematic support" when encoding new associations (see Craik \& Bosman, 1992). This may similar to older adults being better at remembering related words pairs, but in the context of more naturalistic materials. However, it is evident that value can influence the ability to remember associations, and older adults might focus on associative information only when this conveys critical information that is consistent with goals.

\section{Recollection, Familiarity, and Value}

One reason for older adults' associative memory impairments may be the failure to utilize more detailed recollective processing at retrieval, and instead rely on familiarity, which can lead to false memory errors (Jacoby \& Rhodes, 2006). Jacoby and colleagues have used the process dissociation procedure to investigate the contributions of recollection and familiarity, and consistently 
find that older adults rely more on familiarity, presumably due to deficits in recollection (see Yonelinas, 2002, for a review), although this is amenable to training in some circumstances (Jennings \& Jacoby, 2003). The proposed model and strategic and selective control theory also illustrates situations in which older adults use familiarity at retrieval. However, as is often the case for older adults, unopposed reliance on familiarity can lead to a variety of errors and biases on memory tests, and the model suggests this is related to coarse grain size of information specificity at retrieval.

Although recollection is thought to be a slower, more controlled and detailed retrieval process, and impaired in old age (Light, Prull, La Voie, \& Healy, 2000; Yonelinas, 2002), there are situations in which older and younger adults exhibit a similar reliance on familiarity (e.g., Benjamin \& Craik, 2001). For older adults, a reliance on familiarity may be a necessary and adaptive shift based on an awareness of deficits in recollection. Age-related deficits in recollection are observed for verbal materials that differ slightly from study to test (e.g., knee-bend and kneebone). Older adults' use of familiarity does not allow for the differentiation between similar verbal materials at test. However, older adults can improve with specific training and feedback in this type of procedure (Rhodes, Jacoby, Daniels, \& Rogers, 2007), and especially when other more naturalistic, nonverbal materials are used, familiarity seems to be used by both younger and older adults. For example, Bastin and Van der Linden (2006) used unfamiliar faces and found that both younger and older adults used familiarity to a similar extent on a recognition test. Rhodes, Castel, and Jacoby (2006) also reported that familiarity was a strong contributor for memory for previously presented face pairs, as both younger and older adults displayed high error rates for rearranged pairs, which consisted of two previously presented faces that were not paired together at encoding.

When materials are somewhat conducive to the use of familiarity, both younger and older adults engage in this type of familiarity-based processing, and it may be the case that older adults also use familiarity for word pairs for similar reasons. Although familiarity can lead to a number of memory errors and considerable frustration (e.g., a face is familiar, but where do I know this person from?), it may be that older adults can benefit from this initial familiarity to eventually engage later details of retrieval, although on most laboratorybased memory tests this can result in errors. Multhaup (1995) did find an exception to this by providing older adults with more detailed response options that allowed them to be more aware of familiarity-based errors, and Roediger and Geraci (2007) similarly found a decrease in misinformation errors when older adults were given practice with the retrieval of source information, thus avoiding the use of familiarity. 


\section{E. False Memory and Flexible Remembering}

There is also evidence to suggest that older adults rely on more gist-based memory, which refers to a highly abstracted and semantically rich representation of the past, relative to more specific verbatim memory, which is memory for the exact sensory inputs of a given situation in the past (e.g., Reder et al., 1986). Fuzzy-trace theory (Brainerd \& Reyna, 2001) suggests that with age the ability to retain verbatim information deteriorates more quickly than the ability to retain gist information (e.g., Schacter, Koutstaal, Johnson, Gross, \& Angell, 1997; Titcomb \& Reyna, 1995; Tun, Wingfield, Rosen, \& Blanchard, 1998). For example, in the Deese/Roediger/McDermott (DRM) paradigm (Deese, 1959; Roediger \& McDermott, 1995), older adults are more likely to falsely remember the critical semantic associate (a highly related member of the semantic class which makes up the study list but was not actually presented at study) than younger adults on both recognition (Balota et al., 1999; Koutstaal \& Schacter, 1997; Norman \& Schacter, 1997) and recall (Kensinger \& Schacter, 1999; Norman \& Schacter, 1997; Tun et al., 1998) tasks. This suggests age-related reliance of gist memory or age-related declines in verbatim memory (Brainerd \& Reyna, 2001), or age-related differences in semantic activation and monitoring at retrieval (Balota et al., 1999).

There are circumstances in which older adults can reduce false memory errors. Tun et al. (1998) observed that age-related differences decreased when all participants were encouraged, through task demands, to rely on a gist representation of the study list. McCabe and Smith (2002) have also shown that older adults can reduce false alarms to the critical lure if warned prior to the encoding session about the nature of the task and materials. This suggests that although older adults may typically rely on gist-based representations, under certain conditions they are able to access and use more specific information. Such findings are consistent with the data previously described showing that older adults can remember gist-based information about grocery prices, as well as more specific information about market-value prices (e.g., Castel, 2005), by relying on schemas and evaluative processing.

The findings from the DRM paradigm might also indicate that older adults can focus on integrating-related units of information to a more general grain size, leading to false memory errors, but also somewhat useful gist-based memories of the past. For example, Adams (1991) has shown that for text recall, memory became more reconstructive (using prior knowledge to supplement recall) in old age, and included more elaborations and metaphoric prepositions, perhaps indicating that older adults place more value on this manner of recall when communicating information. Interestingly, younger experts are also prone to false recall of information within their domain of expertise (Castel, McCabe, Roediger, \& Heitman, 2007) 
suggesting that this effect may be driven in part by prior knowledge supplementing (and interfering with) the processes involved in accurate memory performance. Thus, if both younger experts and older adults are prone to these types of errors, one could make the claim that older adults use memory in an expert-like fashion, which results in efficient memory performance, but with the side effect of gist-based and domain-specific memory errors.

Although gist-based processing can lead to memory errors, especially for older adults, it allows for the transfer of learning to new situations and to complex forms of thought such as using analogies and drawing inferences based on the classification of events and objects (e.g., Caplan \& Schooler, 2001; Reder et al., 1986). Although older adults seem to rely on gist-based processing, the ability to switch between gist recall and recollection of details is a critical function, and this has been referred to as "flexible remembering" (Koutstaal, 2006). Koutstaal (2006) has provided further evidence that older adults utilize gist-based representations, and that the ability to switch between these two forms of remembering is present in younger adults, but also to a lesser extent for older adults. This suggests that gist-based processing may be a default mode of encoding and retrieval by older adults, even though older adults can and do encode details (Koutstaal, 2003), as evidence by priming studies (e.g., Light et al., 2000). Given that Adams and colleagues (1991; Adams, Smith, Nyquist, and Perlmutter (1997) have shown that older adults recall the gist of stories, as well as more interpretative information, whereas younger adults are better at recalling specific details of the story, it suggests that older adults use memory in different ways, especially in terms of the abstraction and retrieval of gist. For example, older adults might quickly decompose specific information to a more general, manageable gist-based form, such as remembering that a new television costs "about $\$ 4000$," rather than the more specific and accurate price of $\$ 3989$. What remains to be understood is if gist-based processing is an adaptive form of remembering for older adults (cf. Schacter, 1999), and if older adults can utilize more detailed processing for high value information. The evidence from emotional processing, and other circumstances that involve evaluative processing seems to suggest that under some conditions older adults can recruit these processes, but only in situations that dictate the need and opportunity to avoid familiarity- or gist-based memory errors.

\section{F. Proper Names as Low Value Information?}

Memory for proper names is one of the most noticeable memory impairments that typically accompanies aging (see James, 2006; Rendell, Castel, \& Craik, 2005). Although proper name retrieval is one of the chief complaints of older 
adults, and likely represents one of the critical memory impairments that older adults face, the consequences of not being able to recall other pertinent information about a target individual might be more severe. For example, not being able to recall a person's name, but remembering other details (e.g., their profession, that they have two children, they drive an expensive sports car, they are someone you can confide in, etc.) is often more valuable and critical for future interactions with this person (despite the embarrassment of forgetting their name); thus, proper name memory impairments might be somewhat adaptive in light of then being able to focus on the encoding and recall other more pertinent associated details.

If proper names contained higher value information, older adults might be more prone to pay attention to this type of information, as it would be given a certain degree of priority. In terms of emotion and binding, MacKay and colleagues suggest a priority-binding theory, in which arousing stimuli trigger emotional reactions that prioritize the process of binding that item to its context (Hadley \& MacKay, 2006; MacKay \& Ahmetzanov, 2005; MacKay et al., 2005). According to the priority-binding theory (MacKay et al., 2005), when a word is seen during a list-learning task, a binding node is primed to form connections between the episodic context and the word meaning. When the word is arousing, relative to other words that are presented in rapid fashion, activation of other currently primed binding nodes is delayed until binding for the higher priority emotional item is complete (Hadley \& MacKay, 2006). In the context of proper name encoding and retrieval, it is likely that other more salient information is given priority when someone is introduced (a time when most proper name encoding occurs in everyday interaction), but the name is given lower priority relative to other important or emotional information about the person.

It is important to note that even when proper name information contains semantic information (e.g., Mr. Barber is a Baker), both younger and older adults show impairments for the proper name relative to the occupation information (Rendell et al., 2005). Craik (2002) suggests that as to-be-remembered information becomes more specific, age-related differences in memory performance become more apparent, with proper names representing highly specific and arbitrary types of information. Older adults might only be able to encode and retrieval proper names in situations in which proper names carry significant meaning or importance for future use, or convey some emotional component, which is very rarely the case. However, this type of impairment might seem efficient (although very frustrating) if one needs to retain other higher value information at the expense of recalling a proper name. 


\section{G. Memory, Value, and Grain Size at Retrieval}

Turning to retrieval, and the final stage in the proposed model that focuses on grain size, the findings from the false memory/DRM literature suggest that older adults may utilize gist-based encoding and retrieval operations under certain situations, but it remains unclear why older adults use gist processing as opposed to relying on verbatim information. Although a general reduction in available processing resources may partially explain the reliance on gist, older adults may be able to maximize memory performance using appropriate "grain-size" analysis (Koriat \& Goldsmith, 1996; Goldsmith et al., 2002; Goldsmith and Koriat, this volume) in conjunction with environmental and schematic support. Control over grain size can be defined as the operation in which one chooses the level of detail ("precision") or generality ("coarseness") at which to encode and later report remembered information (Goldsmith et al., 2002). For example, if one witnesses a crime and attempts to remember certain characteristics of the assailant, one could encode (and/or later retrieve) precise information such as "the man was precisely $5 \mathrm{ft}, 10 \mathrm{in}$. tall," or more general information, such as the man was "about $6 \mathrm{ft}$ tall," or "about my height."

Goldsmith et al. (2002), and Goldsmith and Koriat (this volume) highlight an important distinction between memory accuracy and memory quantity, such that people can withhold information that they might feel unsure about or provide relatively coarse information that is unlikely to be wrong, or fits appropriately with the situation. According to this notion, the rememberer has the ability to strategically control and regulate the grain size of their answers to accommodate the competing goals of accuracy and informativeness, suggesting that grain size is mediated by both cognitive and metacognitive processes. It may also be the case that expertise in a particular domain gives the rememberer more control over grain size, leading to better memory accuracy, as was the case with older adults being able to remember the exact price of market-value grocery items, but only the range of other unrealistic prices (Castel, 2005). Although retrieval precision is not typically emphasized when evaluating memory changes in older adults (but see Burke \& Light, 1981), it is important to understand how strategic control and monitoring at retrieval and grain size is related to evaluative processing at encoding, and if older adults can avoid memory errors by using appropriate grain size.

For older adults, monitoring at retrieval does not necessarily lead to more effective and accurate retrieval (e.g., Rhodes \& Kelley, 2005) and that this can also lead to differential trade-offs in terms of quantity and accuracy. For example, Kelley and Sahakyan (2003) found that older adults were substantially less accurate than young adults in free report cued recall, 
which may be a more precise form of remembering; however, both older and younger adults made gains in memory accuracy from forced report to free report, but older adults did so at the expense of greater losses in quantity correct. However, like most memory paradigms, this did not involve a form of differential value at encoding (although Kelley and Sahakyan did manipulate incentives for accuracy), which could possibly lead to strategic opportunities for older adults to use memory in an optimal manner.

The findings from studies such as those from the false memory/DRM literature suggest that it may be the case that older adults choose or are forced to employ a broader "grain-size" analysis during both encoding and retrieval operations. This may lead to what appear to be impairments in terms of memory for specific items and associative information. For example, older adults could recall which grocery items were paired with prices that were incongruent with expectations (a broad grain size), but had greater difficulty remembering the precise price of these over- or underpriced items (a more fine-grained analysis). Thus, as indicated in the model, goals can also influence retrieval specificity. Prior knowledge and expertise can fine-tune the level of grain size, such that when prices were market value, older adults could rely on a more specific level of grain size to retrieve the exact price. Why older adults select (or can only use) certain levels of grain size is an important issue to examine in the future, as is looking at agerelated differences in the ability to adaptively and volitionally alter the level of grain-size analysis that is appropriate for the task at hand. It may be that older adults typically use (or can only use) a coarse/broad grain size in certain tasks (such as binding and later recognizing previously studied unrelated word pairs), whereas younger adults can adaptively modify grain size, leading to age-related differences in the ability to remember associative information.

The critical mechanism that has been emphasized in the model is the strategic and adaptive control of encoding operations, which involve the use of value assignment to incoming information in order to direct and bias encoding operations. Based on goals, motivation and prior knowledge, and consistent with the SOC framework, older adults can capitalize on remembering high value information. This information can be represented in most cases in a fairly general form, which is then supplemented with reconstructive processing and prior knowledge, leading to a certain grain size at retrieval. However, in some instances older adults can remember specific information especially if it is deemed to be high value or can be incorporated with goals and prior knowledge and has emotional significance, allowing for the use of recollective processing at retrieval. 


\section{Implications of Value on Memory and Aging}

\section{A. Brain Mechanisms, Value, Memory, and Aging}

How the brain is involved in assigning value and prioritizing information is a critical question, especially in terms of aging and changes in cognitive function. The brain systems involved in memory for emotional information (and the positivity bias in old age) are thought to reflect preserved amygdala function in old age (Mather \& Carstensen, 2005). However, the precise mechanism involved in assigning value to information via evaluative processing is largely unknown. Speculatively, it involves strategic control via frontal lobe function, and communication with hippocampal regions that are involved in binding (i.e., content to value binding). Given the strong emphasis on how goals influence value assignment, this might be somewhat similar to Moscovitch and Winocur's (Moscovitch \& Winocur, 1992) model of "working-with-memory" in which the interaction between frontal and medial temporal lobe functions lead to efficient memory. Older adults display impairments due to poor communication between frontal and medial temporal regions; however, this might be the critical mechanism involved in valuedirected remembering. In the present context, the assignment of value might involve frontal functions, and would include having to "work with" and adapt to impairments that exist in terms of binding in working memory, and communication with medial temporal structures. This can be incorporated with current models that emphasize how adaptive coding integrates the role of prefrontal cortex in working memory (e.g., Duncan, 2001), as well as how cognitive control and the processing of context can be critical for efficient memory performance in old age (e.g., Braver et al., 2001). High value information might gain priority access and communication, at the expense of lower value information. However, the working-with-memory model does not include predictions regarding how value influences memory, a critical point for understanding the brain mechanisms involved in evaluative processing and directed or motivated remembering.

A recent neuroimaging study has shown that value (in the form of monetary incentive presented prior to learning) can lead to differential encoding of high and low value information, via dopamine release in the hippocampus (Adcock, Thangavel, Whitfield-Gabrieli, Knutson, \& Gabrieli, 2006). Adcock et al. (2006) used a procedure much like the selectivity paradigm, in which cues signaled a high (\$5.00) or low (10 cents) value monetary reward for memorizing an upcoming scene. Subjects were tested a day later and were significantly more likely to remember scenes that followed cues for high value rather than low-value reward. In addition, the monetary incentive delay task independently localized regions responsive to reward anticipation. In the 
encoding task, high-reward cues preceding remembered but not forgotten scenes resulted in substantial release of dopamine in the hippocampus, consistent with the notion that reward motivation promotes memory formation via dopamine release in the hippocampus prior to learning. These findings provide a mechanism for value to influence memory performance for younger adults and suggest that value-directed remembering can result in neurochemical variation, leading to better memory based on value activation and reward. Although this specific work has not been extended to older adults (but see Bäckman, Nyberg, Lindenberger, Li, \& Farde, 2006, for a review of aging, dopamine, and memory), it may be that older adults greatly benefit from this dopamine release when value is added to items, resulting in good memory for high value information.

Logan et al. (2002) found that older adults often show activation at encoding of multiple frontal regions in a nonselective and atypical manner (compared to younger adults), resulting in poor memory performance. Thus, critical regions were under recruited, and when under-recruitment was reversed by requiring older adults to use semantic elaboration, memory performance improved, suggesting that older adults can recruit regions when given appropriate direction (see also Cabeza, Anderson, Locantore, \& McIntosh, 2002). In terms of value, it may be that value-directed remembering results in the selective recruitment of critical frontal areas for high value information, leading to efficient memory for high value items but not lower value items. Whereas orienting tasks can improve the recruitment of critical brain regions for older adults, little is known about how value can influence the recruitment and use of these brain regions. Although older adults might not be able to remember as much information in typical settings due to nonselective recruitment, this form of brain region "selectivity" may be improved via value-directed remembering, such that older adults can remember high value information as a result of focusing on important information.

Taken together, and trying to relate these results to value, memory, and aging, these two neuroimaging studies (Adcock et al., 2006; Logan et al., 2002) may suggest that the best way for older adults to remember high value information is to present the value prior to learning (i.e., state that the next bit of information is important to remember), or to emphasize value at the time of study in an incidental manner, allowing for the recruitment of appropriate brain regions. The actual assignment of value might be governed by frontal function, while binding might involve more subcortical structures such as hippocampus and in the case of emotion, the amygdala. For older adults, the subjective assignment of value is somewhat strategic in nature and involves frontal function, while the binding process in old age is more effortful and requires controlled processing, but communication between these areas can result in adaptive control of memory. 


\section{B. Expertise as Adaptive Control and Skilled Cognition in Old Age Revisited}

In light of the previous review and model, it is important to assess how expertise can influence memory performance in old age, possibly via assigning value to information, as well as in a compensatory manner. Expertise in a certain domain can often improve memory performance for domain-specific material, and the idea that this may also reduce age-related memory decline has been widely studied. Previous research on aging, expertise, and memory has shown that expertise can facilitate memory performance for domainrelevant information (see Krampe \& Charness, 2006, for a review). This has been demonstrated in domains such as memory for chess (Charness, 1981), cooking information (Miller, 2003), aviation information (Morrow, Leirer, Altieri, \& Fitzsimmons, 1994), spatial layouts (Hess \& Slaughter, 1990), and music (Meinz \& Salthouse, 1998), although in many cases expertise simply leads to similar benefits in performance for both younger and older adults (see Arbuckle, Cooney, Milne, \& Melchior, 1994). However, given that younger and older adults likely have different goals, it may not be useful to determine when both age groups reach a similar level of performance (e.g., older adults might be satisfied with any expertise-related improvements, even if they do not reach the same levels of younger adults). It may be that expertise leads to the assignment of higher value to certain types of domain-specific information, such that a football score (and remembering the winning team) is better remembered by a football fan because it is of high value, relative to a stock market quote, which might have less relevance to a football fan, but greater value to a broker. The critical endeavor is to better understand how (and why) older adults engage in heuristics to facilitate performance, in light of impairments, and how older adults function like experts in terms of assigning value to information that they deem important, in order to compensate for global memory impairments.

Previously, it was shown that older adults need to adapt to general slowing, and one mechanism involves compensation for slowing via strategic regulation and allocation of cognitive processes. Although not directly in the domain of long-term memory and value, Salthouse (1984) provided convincing evidence for compensatory behavior in a study of expertise and transcription typing. In particular, he showed that older adult transcription typists compensated for declines in perceptual processing speed by looking further ahead in the to-be-typed text than younger adults. Thus, even though older typists were slower, consistent with the generalized slowing hypothesis, they engaged in a strategy that allowed for some compensation. Similarly, Bosman (1993) examined how younger and older adults performed in a task that involved making rapid responses to multiple sequentially presented 
letters that were presented in pairs. She found that older adults strategically engaged in slower responses on the first trial, but would then benefit from this controlled slowing by making more rapid response on the second trial of a pair, resulting in somewhat efficient performance. These findings can be explained by Baltes's selective optimization with compensation model (Baltes, Staudinger, \& Lindenberger, 1999), in that older adults will focus on optimizing performance in an area by using selective compensation. These examples suggest that older adults can exert some strategic control but that this is governed by expertise and heuristics, and this may be related to the value that is placed on speed and accurate performance.

Some older adults may be highly experienced, skilled or even experts in terms of working with changes in memory performance, and using adaptive techniques to combat age-related changes in memory. Thus, older adults who are aware of declines in memory ability may adapt by using strategies that allow them to focus on important information, and this might be considered a form of expertise in terms of the SOC framework. In the present context, older adults might be especially good at selectively assigning low value to many kinds of information that they feel they cannot remember, and then focusing on high value information. Thus, one important form of expertise in terms of dealing with memory changes in old age is the refined ability to successfully allocate value (and thus attention) to high value information, and not to focus on irrelevant information. The variability in this form of expertise (i.e., the ability to engage in evaluative processing) might contribute to the observation that some older adults are more selective in terms of what information they can remember. It could even provide anecdotal evidence for why some dementia patients are capable of seemingly selective memory errors, while remembering certain types of information at inappropriate times, which may have been high value information at another time in life.

\section{Individual Differences Among Older Adults: The Control and Use of Value Assignment}

Older adults may be able to use value to guide encoding and retrieval, but it is likely that there are differences in the extent to which all older adults can efficiently use value in a strategic manner. As a group, older adults differ on an array of variables (see Nyberg \& Bäckman, 2006), including areas such as working memory capacity and inhibitory control (Hasher \& Zacks, 1988), and these variables may relate to how well an individual can use value to guide encoding and retrieval operations. Thus, assignment of value may be the critical role that "cognitive control" plays in cognitive aging. Some older adults may be better at recruiting appropriate brain networks for compensation (e.g., Cabeza et al., 2002) and this might be accomplished via value-directed remembering. 
Also, older adults need to use prospective memory in many cases in terms of knowing what information will be of high value at a later time, depending on whether value assignment and later retrieval is strategic and self-initiated, or more automatic (e.g., Einstein, McDaniel, Richardson, Guynn, \& Cunfer, 1995).

Evaluative processing at encoding can ideally lead to older adults being selective about what information they encode for future use, but it is clear that this process does not lead to all older adults simply ignoring low value or task irrelevant information. Impairments may thus exist in terms of cognitive control at initial encoding stages, while a higher level control system (strategic control in light of value) then leads to older adults focusing on higher value information, despite perceptual or lower value information still being registered. It may be that within a general older adult population, individual differences exist in terms of the degree to which strategic control can override if/how low value or task irrelevant information is encoded. This ability might be related to frontal lobe function, working memory capacity and the reflexive refresh function in short-term memory suggested by Johnson, Reeder, Raye, and Mitchell (2002; Johnson et al., 2005; see also Mather and Knight 2005, for how measures of cognitive control relate to goal-directed memory).

Although there is a great deal of variability in older adult samples, perhaps one common theme is that older adults try to remember information that they feel is personally relevant or of high value. In their review of aging and long-term memory, Zacks and Hasher (2006) suggest that older adults may actually set their own agendas in terms of what information that they find important or personally useful, and thus may be more discriminating than younger adults. This might involve using more shortcuts or heuristics, relative to younger adults, and can lead to certain kinds of memory errors. However, some of the reviewed studies suggest that older adults can engage in more detailed analytic encoding by using evaluative processing, in the context of how valuable the information is for the older adult.

Older adults are often more inclined to remember options that they have chosen relative to other options in the context of decision making (Mather \& Johnson, 2000), and this might be viewed as adaptive in order to lead to more positive emotion later in life. It also represents how older adults might assign high value to chosen options, given that other nonselected options are likely no longer relevant (thus, now of lower value). This approach of investigating how preferences and personal choice influence how memory is used is an important facet of decision making, as well as how much satisfaction is derived from making decisions consistent with value (e.g., Higgins, 2005). Constructing preferences from memory, as dictated in the "Preferences as Memory" framework (Weber \& Johnson, 2006), emphasizes how preferences and personal choice (i.e., subjective value) can influence and bias decision 
making. Given how older adults can direct memory via value-directed procedures, this might be related to preferences stored in long-term memory. Although "Preferences as Memory" has not been examined in the context of older adults and memory performance, this is certainly an important avenue for future research in cognitive aging, one that can easily incorporate how preferences and value can lead to biases and efficient memory use and decision-making performance by older adults.

\section{Value-Directed Remembering and Implications FOR TRAINING}

Given the variability and decline in memory performance in old age, there is considerable interest in developing training regimens that improve memory performance in old age, and most training studies require large amount of practice in order to acquire significant benefits. Memory performance can also be controlled and improved through the judicious use of mnemonic strategies. For example, imagery and verbal association strategies have been shown to enhance memory in both the laboratory (Verhaeghen, Marceon, \& Goossens, 1992) and real-world situations (West, 1996). Although older adults do not engage in spontaneous strategy use as frequently as younger adults do, their use of a strategy can greatly enhance performance if it is suggested to them (see West, 1996, for a review). The use of strategies requires strong motivation and effort, and although older adults can often see the benefits of using such strategies in the short term, the maintenance of strategy use is short-lived in the real world if motivation and effort are not rewarded (Dunlosky \& Hertzog, 1998; West, 1996).

In terms of processing contextual information that is important for goalrelated behavior, Paxton, Barch, Storandt and Braver (2006) found that age-related differences in context processing can be ameliorated by directed strategy training. However, research on training and expertise has suggested that age-related cognitive sparing is often quite narrow (Kramer \& Willis, 2003), and only being observed on tasks and skills similar to those on which individuals have been trained (i.e., very little transfer to other domains or areas of learning). Ironically, it appears that significant training is often required to begin to use and benefit from memory training (one needs to have practice with training), and this added complication often leads to frustration and lack of reinforcement for older adults. Thus, training needs to be consistent with an individual's need to improve memory in specific ways. Older adults' perceived control of memory ability (e.g., Lachman, 2006) may be critical for the use of effective training procedures, and value-directed remembering may lead to enhancement in the degree of perceived control that older adults experience when working with memory. 
Although there are many situations in which older adults can benefit and exploit other factors that can optimize memory performance, such as exercise and fitness training (Kramer \& Willis, 2003) and being aware that memory is better at optimal time-of-day (typically in the morning, see May, Hasher, \& Stoltzfus, 1993), one missing element is the manner in which training is conceptualized in relation to older adults' goals. Thus, it might not be appropriate to try to coerce older adults to use somewhat unfamiliar and esoteric memory strategies such as make bizarre images or elaboration and somewhat "nonsense" mnemonics, especially for low value information. Developing and implementing appropriate strategies is essential, in the same way that it is not appropriate to give a little league baseball player a 38 ounce baseball bat used by a professional to hit a baseball (i.e., the bat is a powerful tool, but in this case too heavy and not appropriate for a younger player). Although most training is directed toward getting older adults to engage in memory strategies favored by younger adults, a more appropriate goal might be to develop training regimens that build on older adults' strengths, namely the ability to engage in value-directed remembering. For example, Rhodes et al. (2007) found that older adults can improve memory and the accuracy of confidence judgments when given feedback in terms of a value-based score.

Given the distinction between objective and subjective value, it may be important for older adults to focus on objective value in order to enhance memory for detailed information, since subjective value assignment is already under the control of the individual. In general, training regimens might focus on teaching both younger and older adults how to prioritize what is committed to memory, via value-directed remembering. It appears that younger adults often have difficulty knowing what is important to remember for future tests (but have very little problem memorizing large amounts of information), while older adults under certain circumstances seem to be able to prioritize according to reductions in the ability to remember vast amounts of new information. Thus, both age groups can benefit from learning and implementing principles related to selection, prioritizing, and value-directed remembering.

\section{Summary and Conclusions}

Neisser (1982) wrote that cognitive psychology needs to address the "important" question related to memory, leading to a cognitive revolution that generated great debate as to what were the important questions regarding memory, and the methodology that would be needed to answer these questions. Twenty-five years since Neisser has stated this claim, research in cognitive aging might be faced with a similar challenge. Research in cognitive 
aging can tell us a great deal about memory impairments, but we also need to be aware of how older adults strategically use memory in efficient ways in light of impairments. Older adults may feel the need to focus on the important things to remember, given a long life span of encountering information, and the knowledge that life, as well as memory resources, is limited (Carstensen, 2006). Thus, Neisser's research perspective is also somewhat related to how older adults begin to view their memory, by identifying what is important and focusing on these aspects. Although value can take various forms, and be assigned both objectively and subjectively, it may be useful to draw on the diamond-water paradox that was presented earlier in the context of Adam Smith's objective or intrinsic theory of value. It may be the case that while younger adults can focus on detailed memory of many events (perceived as high value but not always functional information, akin to a diamond), older adults focus on more functional, gist-based, and perhaps more practical and positive information (what they feel is necessary for a sustainable existence and enjoyable survival, much like water). A functional approach to how older adults direct resources to certain kinds and types of information, in relation to value and strategic and selective control theory, will likely be a fruitful manner to study age-related change across the life span in order to understand the impairments, biases and benefits that accompany memory performance in old age.

Although this chapter presents a somewhat (overly?) optimistic outlook regarding how older adults can efficiently use memory in old age, these arguments are made in response to the obvious memory impairments that older adults face. Decades of research have shown numerous types of specific deficits and disproportionate impairments in a variety of memory tasks, both naturalistic and laboratory-based, most of which are not ameliorated by training strategies. This might be one of the most universal findings in cognitive aging - but this story needs to be interpreted in a framework that emphasizes life span development. Although it does not come as a surprise that at the age of 60 years most of us cannot run as fast as we could at the age of 16 years, changes in certain kinds or speed of memory performance need to be interpreted in the context of how they can influence, not simply impair, the use of memory in old age. The present chapter emphasizes that what is critical is the adaptive nature of human memory, and how memory can function in light of the value placed on the information. Given that the adult life span has increased significantly over the past few decades, memory must adapt to cope with living longer. Carstensen and Charles (2002) argue that even good news (living longer) is taken in a somewhat negative tone (poorer memory and cognitive function) - a perspective that is often taken by younger but not older adults. What is important to study is how older adults adaptively cope with longer life span, 
and how value plays a critical role in maximizing memory performance, and well-being in general.

The present arguments suggest that as we get older we start to use our memory in different ways, focusing on what we deem important in light of knowing that we cannot remember everything (or in many situations, most things). This does not just start at the age of 65 years, as many of us need to prioritize and effortfully direct attention to PIN numbers, passwords, and learning new names, even at the "young" age of 30 years, often relying on (electronic) devices to help remember critical information. Anecdotally, older adults (as well as younger adults, to a certain degree) will remark that although they have difficulty remembering information, "if it is important, then I will remember it." Thus, perhaps one benefit of old age and wisdom is learning what is important in life and then directing resources to achieve these goals.

Memory impairments clearly exist in old age, but older adults can exert some degree of strategic control via evaluative processing to direct cognitive resources to high value or high priority information. William James (1890) commented on this, arguing that "Selection is the very keel on which our mental ship is built. And in the case of memory its utility is obvious. If we remembered everything, we should on most occasions be as ill off as if we remembered nothing"' (p. 680). Although this quote puts the case for selectivity rather strongly (and James might have been noticing his own agerelated change in memory at the time?!), it does emphasize the need to be selective when trying to remember new information, especially in old age. This process may lead to efficient memory performance in light of reductions in processing speed or capacity, and may lead older adults to be more discriminating about what kinds of information are committed to memory. In some cases this may lead to gist-based processing, or the reliance on familiarity in the absences of more detailed recollection. Older adults' bias to focus on processing high value information coupled with prior knowledge to supplement memory, or remembering important positive information at the expense of other details, can lead to the efficient and effective use of memory during the adult life span.

\section{ACKNOWLEDGMENTS}

I thank both Lynn Hasher and Gus Craik for engaging discussions and debates regarding memory and cognitive aging, which forced me to take a new approach to how I think about studying memory and aging, and provided some of the motivation for this perspective and line of research. I also acknowledge the influence of Paul Baltes, who has influenced how I thought about aging before I began to study aging. I specifically thank David McCabe and Matthew Rhodes for extremely useful comments, as well as the following people who have provided 
encouragement, and critical views in response to the arguments made in the present work: Aaron Benjamin, Laura Carstensen, Boris Castel, Judy Gold, Jessica Logan, Don MacKay, and Rose Zacks. Finally, I am continually grateful for the insight of many older adults, who seem to learn and know valuable information about their own memory.

\section{REFERENCES}

Adams, C. (1991). Qualitative age difference in memory for text: A lifespan developmental perspective. Psychology and Aging, 6, 323-336.

Adams, C., Smith, M. C., Nyquist, L., \& Perlmutter, M. (1997). Adult age-group differences in recall for the literal and interpretive meanings of narrative test. Journal of Gerontology: Psychological Science, 57B, P28-P40.

Adcock, R. A., Thangavel, A., Whitfield-Gabrieli, S., Knutson, B., \& Gabrieli, J. D. E. (2006). Reward-motivated learning: Mesolimbic activation precedes memory formation. Neuron, 50, 507-517.

Arbuckle, T. Y., Cooney, R., Milne, J., \& Melchior, A. (1994). Memory for spatial layouts in relation to age and schema typicality. Psychology and Aging, 9, 467-480.

Bäckman, L., Andersson, J. L., Nyberg, L., Winblad, B., Nordberg, A., \& Almkvist, O. (1999). Brain regions associated with episodic retrieval in normal aging and Alzheimer's disease. Neurology, 52, 1861-1870.

Bäckman, L., Nyberg, L., Lindenberger, U., Li, S.-C., \& Farde, L. (2006). The correlative triad among aging, dopamine, and cognition: Current status and future prospects. Neuroscience and Biobehavioral Reviews, 30, 791-807.

Balota, D. A., \& Faust, M. E. (2001). Attention in dementia of the Alzheimer's type. In F. Bolla and S. Cappa (Eds.), Handbook of neuropsychology: Vol. 6. Aging and dementia (2nd ed., pp. 51-80). New York, NY: Elsevier Science.

Balota, D. A., Cortese, M. J., Duchek, J. M., Adams, D. R., Roediger, H. L., III, McDermott, K. B., et al. (1999). Veridical and false memories in healthy older adults and in dementia of the Alzheimer's type. Cognitive Neuropsychology, 16, 361-384.

Balota, D. A., Dolan, P. O., \& Duchek, J. M. (2000). Memory changes in healthy young and older adults. In E. Tulving and F. I. M. Craik (Eds.), The Oxford handbook of memory (pp. 395-410). Oxford University Press.

Baltes, P. B., \& Baltes, M. M. (1990). Psychological perspectives on successful aging: The model of selective optimization with compensation. In P. B. Baltes and M. M. Baltes (Eds.), Successful aging: Perspectives from the behavioral sciences (pp. 1-34). New York, NY: Cambridge University Press.

Baltes, P. B., Staudinger, U. M., \& Lindenberger, U. (1999). Lifespan psychology: Theory and application to intellectual functioning. Annual Review of Psychology, 50, 471-507.

Bastin, C., \& Van der Linden, M. (2006). The effects of aging on the recognition of different types of associations. Experimental Aging Research, 32, 61-77.

Benjamin, A. S. (2007). Memory is more than just remembering: Strategic control of encoding, accessing memory, and making decisions. In A. S. Benjamin and B. H. Ross (Eds.), The psychology of learning and motivation (Vol. 48, pp. 175-223). San Diego, CA: Academic Press.

Benjamin, A. S., \& Craik, F. I. M. (2001). Parallel effects of aging and time pressure on memory for source: Evidence from the spacing effect. Memory \& Cognition, 29, 691-697.

Blanchard-Fields, F. (2007). Everyday problem solving and emotion: An adult developmental perspective. Current Directions in Psychological Science, 16, 26-31. 
Blanchard-Fields, F., \& Camp, C. J. (1990). Affect, individual differences, and real world problem solving across the adult life span. In T. Hess (Ed.), Aging and cognition: Knowledge organization and utilization (pp. 461-497). Oxford, England: North Holland.

Bosman, A. A. (1993). Age and skill differences in typing related and unrelated reaction time tasks. Aging and Cognition, 1, 310-322.

Brainerd, C. J., \& Reyna, V. F. (2001). Fuzzy-trace theory: Dual-processes in reasoning, memory, and cognitive neuroscience. Advances in Child Development and Behavior, 28, 49-100.

Braver, T. S., Barch, D. M., Keys, B. A., Carter, C. S., Kaye, J. A., Janowsky, J. S., et al. (2001). Context processing in older adults: Evidence for a theory relating cognitive control to neurobiology in healthy aging. Journal of Experimental Psychology: General, 130, 746-763.

Burke, D. M., \& Light, L. L. (1981). Memory and aging: The role of the retrieval processes. Psychological Bulletin, 90, 513-546.

Cabeza, R. E., Anderson, N. D., Locantore, J. K., \& McIntosh, A. R. (2002). Aging gracefully: Compensatory brain activity in high-performing older adults. Neuroimage, 17, 1394-1402.

Caplan, L. J., \& Schooler, C. (2001). Age effects on analogy-based memory for text. Experimental Aging Research, 2, 151-165.

Carstensen, L. L. (1992). Social and emotional patterns in adulthood: Support for socioemotional selectivity theory. Psychology and Aging, 7, 331-338.

Carstensen, L. L. (2006). The influence of a sense of time on human development. Science, 312, 1913-1915.

Carstensen, L. L., \& Charles, S. T. (2002). Human aging: Why is even good news taken as bad? In L. Aspinwall and U. Staudinger (Eds.), A psychology of human strengths: Perspectives on an emerging field. Washington, DC: American Psychological Association.

Carstensen, L. L., Isaacowitz, D. M., \& Charles, S. T. (1999). Taking time seriously: A theory of social selectivity. American Psychologist, 54, 165-181.

Castel, A. D. (2005). Memory for grocery prices in younger and older adults: The role of schematic support. Psychology and Aging, 20, 718-721.

Castel, A. D. (2007). Aging and memory for numerical information: The role of specificity and expertise in associative memory. Journal of Gerontology: Psychological Sciences, 62, 194-196.

Castel, A. D., Benjamin, A. S., Craik, F. I. M., \& Watkins, M. J. (2002). The effects of aging on selectivity and control in short-term recall. Memory \& Cognition, 30, 1078-1085.

Castel, A. D., \& Craik, F. I. M. (2003). The effects of aging and divided attention on memory for item and associative information. Psychology and Aging, 18, 873-885.

Castel, A. D., Balota, D. A., Hutchison, K. A., Logan, J. M., \& Yap, M. J. (2007). Spatial attention and response control in healthy younger and older adults and individuals with Alzheimer's disease: Evidence for disproportionate selection breakdowns in the Simon task. Neuropsychology, 21, 170-182.

Castel, A. D., Farb, N., \& Craik, F. I. M. (2007). Memory for general and specific value information in younger and older adults: Measuring the limits of strategic control. Memory \& Cognition. (in press).

Castel, A. D., McCabe, D. P., Roediger, H. L. III, \& Heitman, J. L. (2007). The dark side of expertise: Domain specific memory errors. Psychological Science, 18(1), 3-5.

Chalfonte, B. L., \& Johnson, M. K. (1996). Feature memory and binding in young and older adults. Memory \& Cognition, 24, 403-416.

Charness, N. (1981). Visual short-term memory and aging in chess players. Journal of Gerontology, 36, 615-619. 
Craik, F. I. M. (2002). Human memory and aging. In L. Bäckman and C. von Hofsten (Eds.), Psychology at the turn of the millennium (pp. 261-280). Hove, UK: Psychology Press.

Craik, F. I. M., \& Bosman, B. A. (1992). Age-related changes in memory and learning. In H. Bouma and J. A. M. Graafmans (Eds.), Gerontechnology (pp. 79-92). Amsterdam: IOS Press.

Craik, F. I. M., \& Byrd, M. (1982). Aging and cognitive deficits: The role of attentional resources. In F. I. M. Craik and S. E. Trehub (Eds.), Aging and cognitive processes. New York, NY: Plenum.

Craik, F. I. M., \& Salthouse, T. A. (2000). The handbook of aging and cognition. Hillsdale, NJ: Lawrence Erlbaum.

Deese, J. (1959). On the prediction of occurrence of particular verbal intrusions in immediate recall. Journal of Experimental Psychology, 58, 305-312.

Diehl, M., Coyle, N., \& Labouvie-Vief, G. (1996). Age and sex differences in strategies of coping and defense across the life span. Psychology and Aging, 11, 127-139.

Duncan, J. (2001). An adaptive coding model of neural function in prefrontal cortex. Nature Reviews Neuroscience, 2, 820-829.

Dunlosky, J., \& Connor, L. (1997). Age-related differences in the allocation of study time account for age-related differences in memory performance. Memory \& Cognition, 25, 691-700.

Dunlosky, J., \& Hertzog, C. (1998). Training program to improve learning in later adulthood: Helping older adults educate themselves. In D. J. Hacker, J. Dunlosky, and A. C. Graesser (Eds.), Metacognition in educational theory and practice (pp. 249-275). Mahwah, NJ: Lawrence Erlbaum.

Dunlosky, J., Kubat-Silman, A. K., \& Hertzog, C. (2003). Training monitoring skills improves older adults' self-paced associative learning. Psychology and Aging, 18, 340-345.

Einstein, G. O., McDaniel, M. A., Richardson, S. L., Guynn, M. J., \& Cunfer, A. R. (1995). Aging and prospective memory: Examining the influence of self-initiated retrieval processes. Journal of Experimental Psychology: Learning, Memory, and Cognition, 21, 996-1007.

Freund, A. M., \& Baltes, P. B. (2002). Life-management strategies of selection, optimization, and compensation: Measurement by self-report and construct validity. Journal of Personality and Social Psychology, 82, 642-662.

Fung, H. H., \& Carstensen, L. L. (2003). Sending memorable messages to the old: Age differences in preferences and memory for advertisements. Journal of Personality and Social Psychology, 85, 163-178.

Goldsmith, M., \& Koriat, A. (2007). The strategic regulation of memory accuracy and informativeness. In A. S. Benjamin and B. H. Ross (Eds.), The psychology of learning and motivation (Vol. 48, pp. 1-60). San Diego, CA: Academic Press.

Goldsmith, M., Koriat, A., \& Weinberg-Eliezer, A. (2002). Strategic regulation of grain size in memory reporting. Journal of Experimental Psychology: General, 131, 73-95.

Grühn, D., Smith, J., \& Baltes, P. B. (2005). No aging bias favoring memory for positive material: Evidence from a heterogeneity-homogeneity list paradigm using emotionally toned words. Psychology and Aging, 20, 579-588.

Hadley, C. B., \& MacKay, D. G. (2006). Does emotion help or hinder immediate memory? Arousal versus priority-binding mechanisms Journal of Experimental Psychology: Learning, Memory, and Cognition, 32, 79-88.

Hasher, L., \& Zacks, R. T. (1988). Working memory, comprehension and aging: A review and a new view. In G. Bower (Ed.), The psychology of learning and motivation (Vol. 22, pp. 193-225). New York, NY: Academic Press.

Heckhausen, J. (1999). Developmental regulation in adulthood: Age normative and sociostructural constraints as adaptive challenges. New York, NY: Cambridge University Press. 
Heckhausen, J., \& Schulz, R. (1995). A life span theory of control. Psychological Review, 102, 284-304.

Hertzog, C., \& Dunlosky, J. (2005). Aging, metacognition, and cognitive control. In B. H. Ross (Ed.), The psychology of learning and motivation (Vol. 45, pp. 215-251). San Diego, CA: Academic Press.

Hertzog, C., Kidder, D. P., Powell-Moman, A., \& Dunlosky, J. (2002). Aging and monitoring associative learning: Is monitoring accuracy spared or impaired? Psychology and Aging, 17, 209-225.

Hess, T. M. (2005). Memory and aging in context. Psychological Bulletin, 131, 383-406.

Hess, T. M., \& Slaughter, S. J. (1990). Schematic knowledge influences on memory scene information in young and older adults. Developmental Psychology, 26, 855-865.

Hess, T. M., Rosenberg, D. C., \& Waters, S. J. (2001). Motivation and representational processes in adulthood: The effects of social accountability and information relevance. Psychology and Aging, 16, 629-642.

Higgins, E. T. (2005). Value from regulatory fit. Current Directions in Psychological Science, 14, 209-213.

Jacoby, L. L. (1999). Ironic effects of repetition: Measuring age-related difference in memory. Journal of Experimental Psychology: Leaning, Memory, \& Cognition, 25, 3-22.

Jacoby, L. L., \& Hay, J. F. (1998). Age-related deficits in memory: Theory and application. In M. A. Conway, S. E. Gathercole, and C. Cornoldi (Eds.), Theories of memory II (pp. 111-134). Hove, UK: Psychology Press.

Jacoby, L. L., \& Rhodes, M. G. (2006). False remembering in the aged. Current Directions in Psychological Science, 15, 49-53.

James, L. (2006). Specific effects of aging on proper name retrieval: Now you see them, now you don't. Journal of Gerontology, Psychological Science, 61, P180-P183.

James, W. (1890). The principles of psychology: Volume 1. New York, NY: Henry Holt.

Jenkins, J. J. (1979). Four points to remember: A tetrahedral model of memory experiments. In L. S. Cermak and F. I. M. Craik (Eds.), Levels of processing in human memory (pp. 429-446). Hillsdale, NJ: Lawrence Erlbaum.

Jennings, J. M., \& Jacoby, L. L. (2003). Improving memory in older adults: Training recollection. Neuropsychological Rehabilitation, 13, 417-440.

Johnson, M. K., Hashtroudi, S., \& Lindsay, D. S. (1993). Source monitoring. Psychological Bulletin, 114, 3-28.

Johnson, M. K., Raye, C. L., Mitchell, K. J., Greene, E. J., Cunningham, W. A., \& Sanislow, C. A. (2005). Using fMRI to investigate a component process of reflection: Prefrontal correlates of refreshing a just-activated representation. Cognitive Affective \& Behavioral Neuroscience, 5, 339-361.

Johnson, M. K., Reeder, J. A., Raye, C. L., \& Mitchell, K. J. (2002). Second thoughts versus second looks: An age-related deficit in reflectively refreshing just-activated information. Psychological Science, 13, 64-67.

Kelley, C. M., \& Sahakyan, L. (2003). Memory, monitoring, and control in the attainment of memory accuracy. Journal of Memory and Language, 48, 704-721.

Kensinger, E. A., \& Schacter, D. L. (1999). When true memories suppress false memories: Effects of aging. Cognitive Neuropsychology, 16, 399-415.

Kensinger, E. A., Piguet, O., Krendl, A. C., \& Corkin, S. (2005). Memory for contextual details: Effects of emotion and aging. Psychology and Aging, 20, 241-250.

Koriat, A., \& Goldsmith, M. (1996). Monitoring and control processes in the strategic regulation of memory accuracy. Psychological Review, 103, 490-517.

Koutstaal, W. (2003). Older adults encode-but do not always use-perceptual details: Intentional versus unintentional effects of detail on memory judgments. Psychological Science, 14, 189-193. 
Koutstaal, W. (2006). Flexible remembering. Psychonomic Bulletin \& Review, 13, 84-91.

Koutstaal, W., \& Schacter, D. L. (1997). Gist-based false recognition of pictures in older and younger adults. Journal of Memory \& Language, 37, 555-583.

Kramer, A. F., \& Willis, S. L. (2003). Cognitive plasticity and aging. In B. H. Ross (Ed.), The psychology of learning and motivation (pp. 267-302). San Diego, CA: Academic Press.

Krampe, R. T., \& Charness, N. (2006). Aging and expertise. In K. A. Ericsson, N. Charness, P. Feltovich, and R. Hoffman (Eds.), Cambridge handbook of expertise and expert performance (pp. 723-742). Cambridge, UK: Cambridge University Press.

Labouvie-Vief, G. (1990). Wisdom as integrated thought: Historical and developmental perspectives. In R. J. Sternberg (Ed.), Wisdom: Its nature, origin, and development (pp. 52-86). New York, NY: Cambridge University Press.

Lachman, M. E. (2006). Perceived control over aging-related declines: Adaptive beliefs and behaviors. Current Directions in Psychological Science, 15, 282-286.

Leippe, M. R., Wells, G. L., \& Ostrom, T. M. (1978). Crime seriousness as a determinant of accuracy in eyewitness identification. Journal of Applied Psychology, 63, 345-351.

Light, L. L., Prull, M. W., La Voie, D. J., \& Healy, M. R. (2000). Dual-process theories of memory in old age. In T. J. Perfect and E. A. Maylor (Eds.), Models of cognitive aging (pp. 238-300). Oxford: Oxford University Press.

Logan, J. M., Sanders, A. L., Snyder, A. Z., Morris, J. C., \& Buckner, R. L. (2002). Underrecruitment and non-selective recruitment: Dissociable neural mechanisms associated with aging. Neuron, 33, 827-840.

MacKay, D. G., \& Ahmetzanov, M. V. (2005). Emotion, memory, and attention in the taboo Stroop paradigm: An experimental analogue of flashbulb memories. Psychological Science, $16,25-32$.

MacKay, D. G., Hadley, C. B., \& Schwartz, J. H. (2005). Relations between emotion, illusory word perception, and orthographic repetition blindness: Tests of binding theory. Quarterly Journal of Experimental Psychology, 58, 1514-1533.

Mather, M. (2006). A review of decision making processes: Weighing the risks and benefits of aging. In L. L. Carstensen and C. R. Hartel (Eds.), When I'm 64 (pp. 145-173). Washington, DC: National Academies Press.

Mather, M. (2007). Emotional arousal and memory binding: An object-based framework. Perspectives on Psychological Science, 2, 33-52.

Mather, M., \& Carstensen, L. L. (2003). Aging and attentional biases for emotional faces. Psychological Science, 14, 409-415.

Mather, M., \& Carstensen, L. L. (2005). Aging and motivated cognition: The positivity effect in attention and memory. Trends in Cognitive Science, 9, 497-502.

Mather, M., \& Johnson, M. K. (2000). Choice-supportive source monitoring: Do our decisions seem better to us as we age? Psychology and Aging, 15, 596-606.

Mather, M., \& Knight, M. (2005). Goal-directed memory: The role of cognitive control in older adults' emotional memory. Psychology and Aging, 20, 554-570.

Mather, M., Knight, M., \& McCaffrey, M. (2005). The allure of the alignable: Younger and older adults' false memories of choice features. Journal of Experimental Psychology: General, 134, 38-51.

May, C. P., Hasher, L., \& Stoltzfus, E. R. (1993). Optimal time of day and the magnitude of age difference in memory. Psychological Science, 4, 326-330.

May, C. P., Rahhal, T., Berry, E. M., \& Leighton, E. A. (2005). Aging, source memory, and emotion. Psychology and Aging, 20, 571-578.

McCabe, D. P., \& Smith, A. D. (2002). The effect of warnings on false memories in young and older adults. Memory \& Cognition, 30, 1065-1077.

McDaniel, M. A., Einstein, G. O., Stout, A. C., \& Morgan, Z. (2003). Aging and maintaining intentions over delays: Do it or lose it. Psychology and Aging, 8, 823-835. 
Meinz, E. J., \& Salthouse, T. A. (1998). The effects of age and experience on memory for visually presented music. Journal of Gerontology: Psychological Science, 53B, P60-P69.

Mikels, J. A., Larkin, G. R., Reuter-Lorenz, P. A., \& Carstensen, L. L. (2005). Divergent trajectories in the aging mind: Changes in working memory for affective versus visual information with age. Psychology and Aging, 20, 542-553.

Miller, L. M. S. (2003). The effects of age and domain knowledge on text processing. Journals of Gerontology: Psychological Sciences, 58, P217-P222.

Morrow, D. G., Leirer, V. O., Altieri, P. A., \& Fitzsimmons, C. (1994). When expertise reduces age differences in performance. Psychology and Aging, 9, 134-148.

Moscovitch, M., \& Winocur, G. (1992). The neuropsychology of memory and aging. In F. I. M. Craik and T. A. Salthouse (Eds.), The handbook of aging and cognition (pp. 315-372). Hillsdale, NJ: Lawrence Erlbaum.

Multhaup, K. S. (1995). Aging, source, and decision criteria: When false fame errors do and do not occur. Psychology and Aging, 10, 492-497.

Nairne, J. S. (2005). The functionalist agenda in memory research. In A. F. Healy (Ed.), Experimental cognitive psychology and its applications: Festschrift in honor of Lyle Bourne, Walter Kintsch, and Thomas Landauer. Washington, DC: American Psychological Association.

Naveh-Benjamin, M. (2000). Adult age differences in memory performance: Tests of an associative deficit hypothesis. Journal of Experimental Psychology: Learning, Memory, and Cognition, 26, 1170-1187.

Naveh-Benjamin, M., Guez, J., Kilb, A., \& Reedy, S. (2004). The associative deficit of older adults: Further support using face-name associations. Psychology and Aging, 19, 541-546.

Naveh-Benjamin, M., Keshet, T., \& Levi, D. (in press). The associative memory deficit of older adults: The role of efficient strategy utilization. Psychology and Aging.

Neisser, U. (1982). Memory: What are the important questions? In U. Neisser (Ed.), Memory observed (pp. 3-19). San Francisco, CA: Freeman.

Norman, K. A., \& Schacter, D. L. (1997). False recognition in younger and older adults: exploring the characteristics of illusory memories. Memory \& Cognition, 25, 838-848.

Nyberg, L., \& Bäckman, L. (2006). Influences of biological and self-initiated factors on brain and cognition in adulthood and aging. In P. B. Baltes, P. A. Reuter-Lorenz, and F. Rösler (Eds.), Lifespan development and the brain: The perspective of biocultural co-constructivism (pp. 239-254). Cambridge: Cambridge University Press.

Park, D. C. (2002). Judging meaning improves function in the aging brain. Trends in Cognitive Sciences, 6, 227-229.

Park, D. C., Smith, A. D., Lautenschlager, G., Earles, J. L., Frieske, D., Zwahr, M., et al. (1996). Mediators of long-term memory performance across the life span. Psychology and Aging, $11,621-637$.

Park, D. C., Lautenschlager, G., Hedden, T., Davidson, N. S., Smith, A. D., \& Smith, P. K. (2002). Models of visuospatial and verbal memory across the adult life span. Psychology and Aging, 17, 299-320.

Park, D. C. and Schwarz, N. (Eds.). (2000). Cognitive aging: A primer. Philadelphia, PA: Psychology Press.

Paxton, J. L., Barch, D. M., Storandt, M., \& Braver, T. S. (2006). Effects of environmental support and strategy training on older adults' use of context. Psychology and Aging, 21, 499-509.

Rahhal, T. A., May, C. P., \& Hasher, L. (2002). Truth and character: Sources that older adults can remember. Psychological Science, 13, 101-105. 
Reder, L. M., Wible, C., \& Martin, J. (1986). Differential memory changes with age: Exact retrieval versus plausible inference. Journal of Experimental Psychology: Learning, Memory, and Cognition, 12, 72-81.

Rendell, P. G., \& Craik, F. I. M. (2002). Virtual week and actual week: Age related differences in prospective memory. Applied Cognitive Psychology, 14, 43-62.

Rendell, P. G., Castel, A. D., \& Craik, F. I. M. (2005). Memory for proper names in old age: A disproportionate impairment? Quarterly Journal of Experimental Psychology, 58 A, 54-71.

Rhodes, M. G., \& Kelley, C. M. (2005). Executive processes, memory accuracy, and memory monitoring: An aging and individual differences analysis. Journal of Memory and Language, 52, 578-594.

Rhodes, M. G., Castel, A. D., \& Jacoby, L. L. (2006). Memory for face pairs: An associative memory impairment? Poster presented at the 47 th annual meeting of the Psychonomics society, Houston, Texas.

Rhodes, M. G., Jacoby, L. L., Daniels, K. A., \& Rogers, C. S. (2007). Training memoryconfidence calibration in the elderly. Manuscript submitted for publication.

Riediger, M., \& Freund, A. M. (2006). Focusing and restricting: Two aspects of motivational selectivity in adulthood. Psychology and Aging, 21, 173-185.

Riediger, M., Li, S.-C., \& Lindenberger, U. (2006). Selection, optimization, and compensation as developmental mechanisms of adaptive resource allocation: Review and preview. In J. E. Birren and K. W. Schaie (Eds.), Handbook of the psychology of aging (6th ed., pp. 289-313). Amsterdam: Elsevier.

Roediger, H. L., \& Geraci, L. (2007). Aging and the misinformation effect: A neuropsychological analysis. Journal of Experimental Psychology: Learning, Memory and Cognition, 34, 1569-1577.

Roediger, H. L., \& McDermott, K. B. (1995). Creating false memories: remembering words not presented in lists. Journal of Experimental Psychology: Learning, Memory, \& Cognition, 20, $1379-1390$.

Salthouse, T. A. (1984). Effects of age and skill in typing. Journal of Experimental Psychology: General, 113, 345-361.

Salthouse, T. A. (1996). The processing-speed theory of adult age difference in cognition. Psychological Review, 103, 403-428.

Schacter, D. L. (1999). The seven sins of memory: Insights from psychology and cognitive neuroscience. American Psychologist, 54, 182-203.

Schacter, D. L., Kaszniak, A. W., Kihlstrom, J. F., \& Valdiserri, M. (1991). The relation between source memory and aging. Psychology and Aging, 6, 559-568.

Schacter, D. L., Koutstaal, W., Johnson, M. K., Gross, M. S., \& Angell, K. A. (1997). False recollection induced by photographs: a comparison of older and younger adults. Psychology and Aging, 12, 203-215.

Smith, A. (1776/1994). The wealth of nations. New York, NY: Random House (Original work published in 1776).

Spencer, W. D., \& Raz, N. (1995). Differential age effects on memory for content and context: A meta-analysis. Psychology and Aging, 10, 527-539.

Spieler, D. H., Mayr, U., \& LaGrone, S. (2006). Outsourcing cognitive control to the environment: Adult age differences in the use of task cues. Psychonomic Bulletin \& Review, 13, 787-793.

Stine, E. L., Wingfield, A., \& Poon, L. W. (1986). How much and how fast: Rapid processing of spoken language in later adulthood. Psychology and Aging, 1, 303-311.

Tentori, K., Osherson, D., Hasher, L., \& May, C. (2001). Wisdom and aging: Irrational preferences in college students but not older adults. Cognition, 81, B87-B96. 
Comp. by: ssumitha Date:6/8/07 Time:13:04:25 Stage:1st Revises File Path:// spiina1001z/womat/production/PRODENV/0000000001/0000004915/

0000000016/0000602775.3D Proof by: QC by: ProjectAcronym:bs:PLM

Volume:48006

Titcomb, A. L., \& Reyna, V. F. (1995). Memory interference and misinformation effects. In F. N. Dempster and C. J. Brainerd (Eds.), Interference and inhibition in cognition (pp. 263-294). San Diego, CA: Academic Press.

Touron, D. R. (2006). Are item-level strategy shifts abrupt of collective? Age differences in cognitive skill acquisition Psychonomic Bulletin \& Review, 13, 781-786.

Tun, P. A., Wingfield, A., Rosen, M. J., \& Blanchard, L. (1998). Response latencies for false memories: gist-based processes in normal aging. Psychology and Aging, 13, 230-241.

Tversky, A. (1969). Intransitivity of preferences. Psychological Review, 76, 31-48.

Tversky, A. (1972). Elimination by aspects. A theory of choice. Psychological Review, 79, 281-299.

Verhaeghen, P., Marceon, A., \& Goossens, L. (1992). Improving memory performance in the aged through mnemonic training: A meta-analytic study. Psychology and Aging, 7, 242-251.

Watkins, M. J., \& Bloom, L. C. (1999). Selectivity in memory: An exploration of willful control over the remembering process. Unpublished manuscript.

Weber, E. U., \& Johnson, E. J. (2006). Constructing preferences from memories. In S. Lichtenstein and P. Slovic (Eds.), The construction of preferences (pp. 397-410). New York, NY: Cambridge University Press.

West, R. L. (1996). Compensatory strategies for age-associated memory impairment. In A. D. Baddeley, B. A. Wilson, and F. N. Watts (Eds.), Handbook of memory disorders (pp. 481-500). London: Wiley.

Wood, S., Busemeyer, J., Koling, A., Cox, C. R., \& Davis, H. (2005). Older adults as adaptive decision makers: Evidence from the Iowa Gambling Task. Psychology and Aging, 20, $220-225$.

Yonelinas, A. P. (2002). The nature of recollection and familiarity: A review of 30 years of research. Journal of Memory and Language, 46, 441-517.

Zacks, R. T., \& Hasher, L. (2006). Aging and long-term memory: Deficits are not inevitable. In E. Bialystok and F. I. M. Craik (Eds.), Lifespan cognition: Mechanisms of change (pp. 162-177). New York, NY: Oxford University Press.

Zacks, R. T., Radvansky, G., \& Hasher, L. (1996). Studies of directed forgetting in older adults. Journal of Experimental Psychology: Learning, Memory, and Cognition, 22, 143-156. 